\title{
The influence of heat production relative to drill wear during osteotomy preparation by different implant drill systems: $A$ comparison study between ceramic and conventional implant drill systems
}

Waleed Alyassin

West Virginia University

Follow this and additional works at: https://researchrepository.wvu.edu/etd

\section{Recommended Citation}

Alyassin, Waleed, "The influence of heat production relative to drill wear during osteotomy preparation by different implant drill systems: A comparison study between ceramic and conventional implant drill systems" (2010). Graduate Theses, Dissertations, and Problem Reports. 4559.

https://researchrepository.wvu.edu/etd/4559

This Thesis is protected by copyright and/or related rights. It has been brought to you by the The Research Repository @ WVU with permission from the rights-holder(s). You are free to use this Thesis in any way that is permitted by the copyright and related rights legislation that applies to your use. For other uses you must obtain permission from the rights-holder(s) directly, unless additional rights are indicated by a Creative Commons license in the record and/ or on the work itself. This Thesis has been accepted for inclusion in WVU Graduate Theses, Dissertations, and Problem Reports collection by an authorized administrator of The Research Repository @ WVU. For more information, please contact researchrepository@mail.wvu.edu. 
The Influence of Heat Production Relative to Drill Wear During Osteotomy Preparation by Different Implant Drill Systems: A Comparison Study Between Ceramic and Conventional Implant Drill Systems

\author{
By \\ Waleed Alyassin D.D.S. \\ Thesis submitted to the School of \\ Dentistry at West Virginia University
}

In partial fulfillment of the requirements for the degree of

\author{
Master of Science \\ in \\ Prosthodontics
}

\author{
Micheal Bagby D.D.S., M.S, Ph.D. \\ Mark W. Richards D.D.S, M.S \\ Ali Kanawati D.D.S., M.S \\ Eros Chaves D.M.D, M.S \\ Morgantown, West Virginia \\ 2010
}

Keywords: Prosthodontics, Implants, Heat, Drills, Ceramic, stainless steel, Wear. 


\title{
ABSTRACT \\ The influence of heat production relative to drill wear during osteotomy prep- aration by different Implant Drill Systems: A comparison Study between ce- ramic and conventional Implant Drill Systems
}

\author{
Waleed Alyassin, D.D.S.
}

Repeated use of implant drills progressively increases their wear and decreases their efficiency, thus producing more frictional heat. Multiple factors have been linked to heat production during surgery including drill sharpness. The purpose of this research is to focus on the heat generated by an implant drill and how the wear factor and the material of the drill effect the heat generated by that drill when drilling through bone.

Two implant drill Systems were evaluated in vitro using bovine back rib bones. Two implant drill system were used. System A was stainless steel surgical drills sizes 2.3, 2.8 and 3.4 mmD (Tapered Screw-Vent surgical drills by Zimmer Dental). System B was alumina-toughened zirconia ceramic surgical drills Sizes were 2.0, 2.8 and 3.5mmD (Thommen Medical). Transverse sections of the bovine bone were obtained. Using a template, one canal $10 \mathrm{~mm}$ long was drilled for the thermocouple. Two marks using a sharp pencil were made next to the thermocouple canal and $0.5 \mathrm{~mm}$ away from the largest final size drill at each site. Sterilization before the first use and after each osteotomy was preformed. Sequential drilling was performed at speed of $1500 \mathrm{Rpm}$ and external irrigation $40 \mathrm{ml}$ saline per min was used. The maximum temperatures were recorded for all the three drills used for the system A and B while maintaining a constant weight of $2.4 \mathrm{~kg}$ applied to the hand piece while drilling. After each trial the drills were sterilized and the preparation repeated twenty five times for each system. All the ostetomies were performed by the same clinician to simulate a real clinical setting situation. Both implant drills system were scanned using Scanning Electron Microscopy before the first and after the last use to evaluate visual wear.

The study showed no significant difference between the two systems from material stand point. Both systems A and B showed an increase in temperature as the drill wear out. It was also found that significant wear occurred to both systems after twenty five usages. The maximum temperature for system A was $31.3^{\circ} \mathrm{C}$ and for system B was $31.2^{\circ} \mathrm{C}$. SEM taking before start and at the end of the study showed significant wear to both systems. Chips and cracking at the drills edges explained the increase in temperature as the drills wears. From this limited in-vitro study, it appears that Implant multiuse drills can be used for a maximum of 25 times without resulting in bone temperature that is harmful. 


\section{TABLE OF CONTENTS}

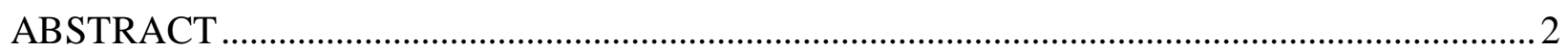

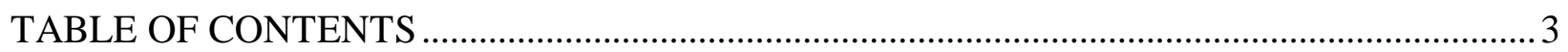

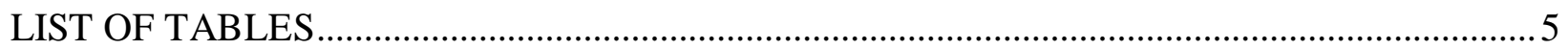

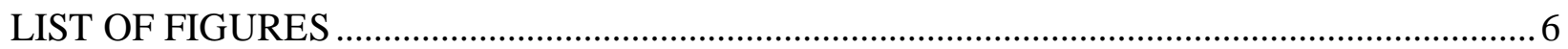

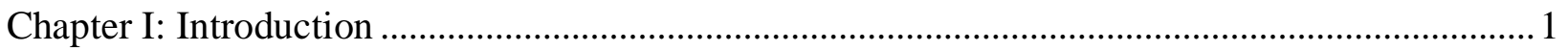

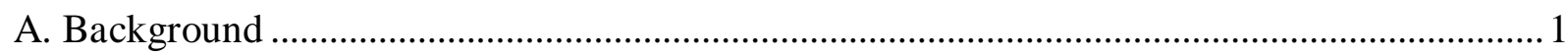

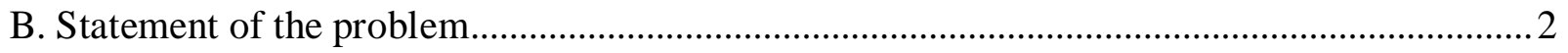

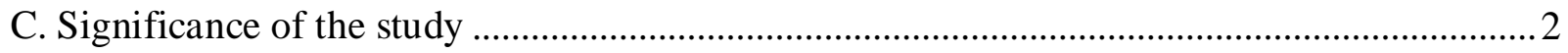

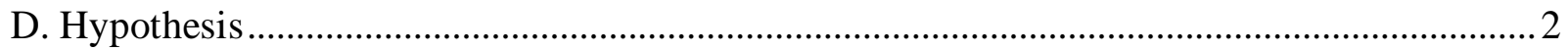

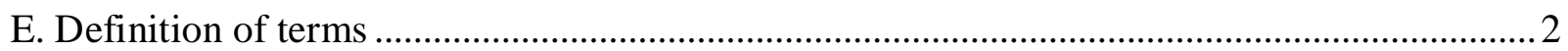

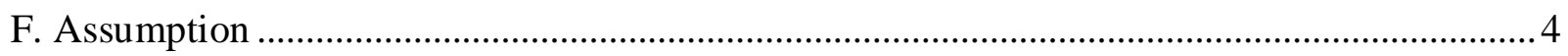

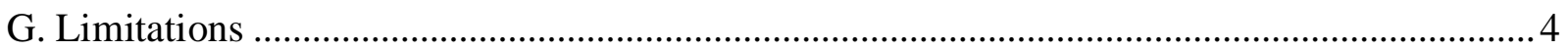

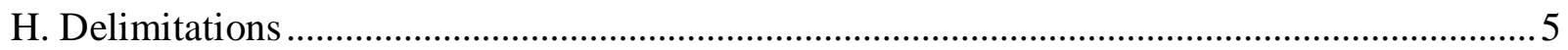

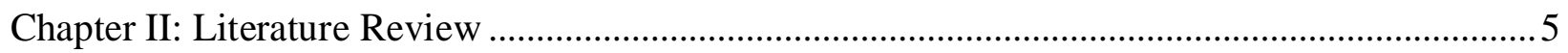

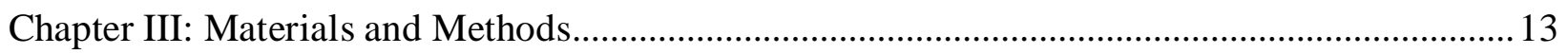

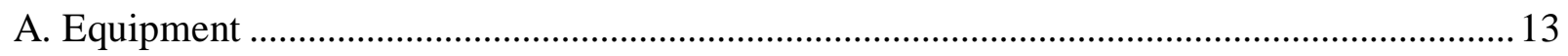

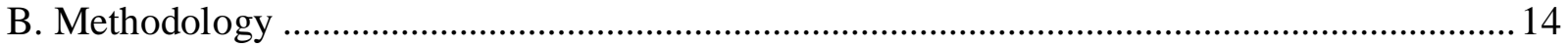

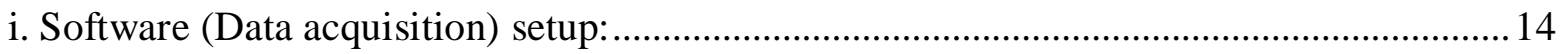




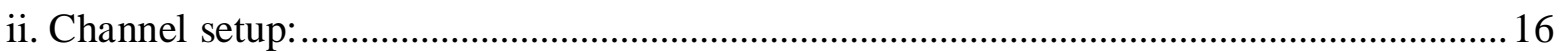

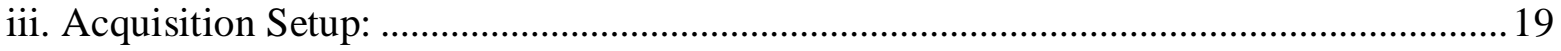

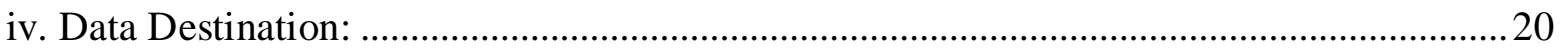

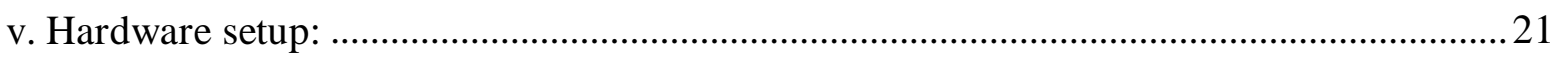

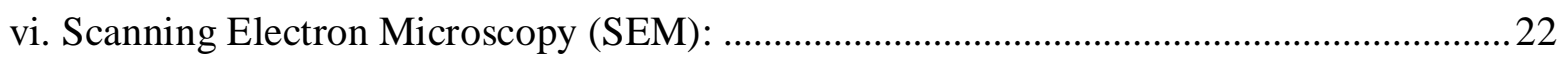

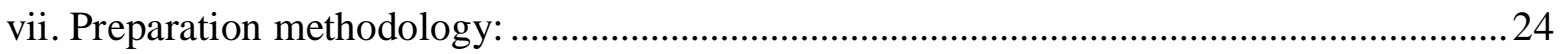

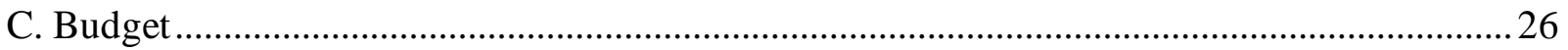

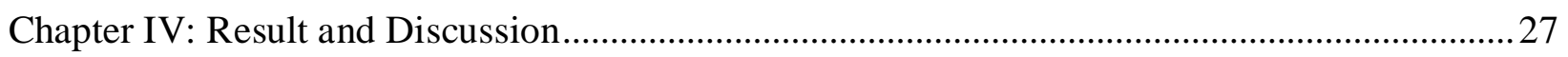

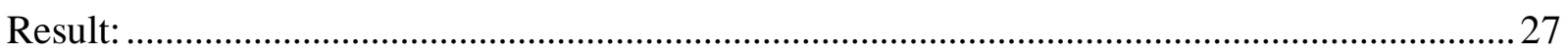

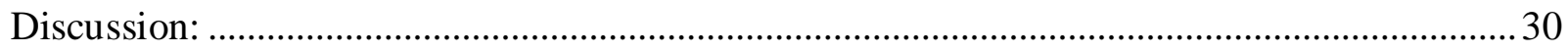

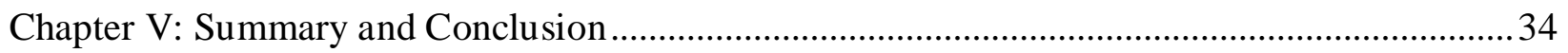

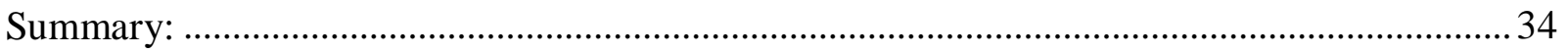

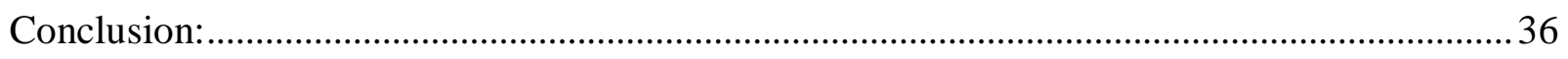

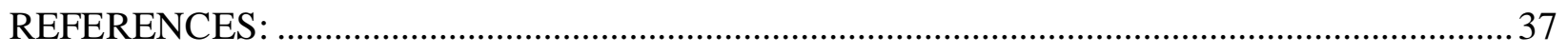




\section{LIST OF TABLES}

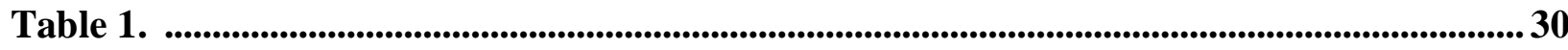




\section{LIST OF FIGURES}

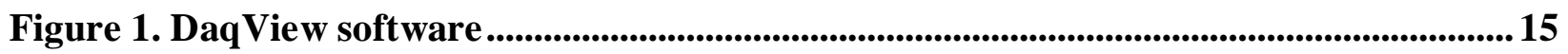

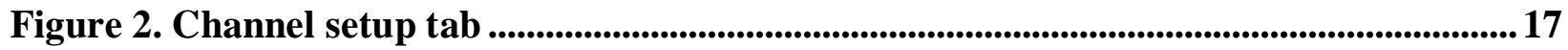

Figure 3. Aquision setup tab .................................................................................................................................. 19

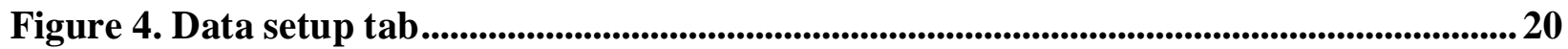

Figure 5. System hardware setup window ..................................................................................21

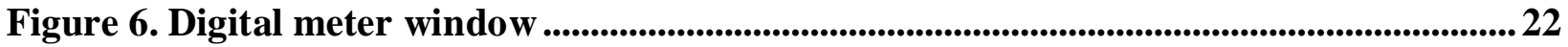

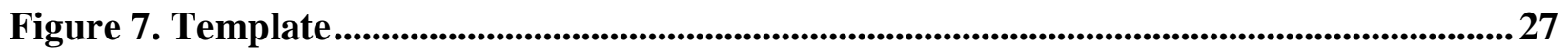

Figure 8. Heat generated with Stainless steel vs. Ceramic ....................................................29

Figure 9. Heat generated with all six drills ...............................................................................................29

Figure 10. Before and after pictures for ceramic drills .................................................... 33

Figure 11. Before and after pictures for stail less steel drills.................................................34 


\section{The influence of heat production relative to drill wear dur- ing osteotomy preparation by different Implant Drill Sys- tems: A comparison study between ceramic and convention- al Implant Drill Systems}

\section{Chapter I: Introduction}

\section{A. Background}

Current dental implant technologies and materials continue to develop at a rapid pace. Dental implants have become established as the procedure of choice when patients are faced with the decision to replace single or multiple teeth. Most restorative and reconstructive dentists can suggest a variety of treatment plans and technologies for replacing any number of teeth. In terms of obtaining optimal restoration of aesthetic appearances and dental function (occlusion, mastication, speaking, etc), implants tend to be unsurpassed. The success rate of implants is in the high ninety percent range. However, occasionally they do fail. Failure due to the surgical technique at time of placement has been attributed to one of the following:

- $\quad$ Overheating the bone while drilling.

- Too much force when they are placed.

- Not enough force when they are placed.

- Contaminated implant.

- Contaminated osteotomy.

- $\quad$ Poor quality of bone.

- Excessive forces during healing. 
The goal of this research is to focus on the heat generated by an implant drill and how the wear factor of the drill effects the heat generated by that drill when drilling through bone. Understanding this factor can help the surgeon in the selection and usage time of specific drills.

\section{B. Statement of the problem}

Does the age and number of uses (wear) after repeated sterilization impact the amount of heat produced by different implant drill systems during surgical site preparation? Do implant drills made of different materials respond to wear differently?

\section{Significance of the study}

The data gathered will show that at the surgical site, the surgeon would be advised to take additional precaution to minimize the chance that necrosis-induced temperatures are generated upon preparation. More careful attention paid to the different implant drill systems and their number of uses at a surgical site could result in fewer implants failures resulting from an osteonecrosis related event. Fewer implants failures as a whole would reduce the overall cost of the implants for both the practitioner and the patient.

\section{Hypothesis}

The increase number of drill uses will result in an increase heat generated by that drill. Different implant drills made of different materials will react differently.

\section{E. Definition of terms}

Bone atrophy: bone resorption noted internally by a decrease in density and externally by an alteration in form. 
Bone factor: relative response of alveolar bone to stimulate or irritation. The ratio of osteogenesis to ostelysis.

Cortical Bone: the peripheral layer of compact osseous tissue.

Corrosion: the loss of elements constituents to the adjacent environment.

Implant: any object or material, such as an alloplastic substance or other tissue, which is partially or completely inserted or grafted into the body for therapeutic, diagnostic, prosthetic, or experimental purposes.

Implant prosthodontics: the phase of prosthodontics concerning the replacement of missing teeth and/or associated structures by restoration that are attached to dental implants.

Implant substructure: the metal framework of an eposteal dental implant that is embedded beneath the soft tissue, in contact with the bone, and stabilized by means of endosteal screw. The periosteal tissue retain the framework to the bone. The framework support the prosthesis, frequently by means of dental implant abutments and other superstructure component.

Implant surgery: the phase of implant dentistry concerning the selection, planning, and placement of the implant body and abutmen.

Implantology: the study or science of placing and restoring dental implants.

Thermonecrosis: localized death of living tissue by heat.

Osteonecrosis: Bone death resulting from poor blood supply to an area of bone. Also known as aseptic necrosis or a vascular necrosis. 
Osteointegration: the apparent direct attachments or connection of osseous tissue to an inert, alloplastic material without intervening connective tissue.

Osteitis: Inflammation of bone.

Osteotomy: the surgical cutting of a bone; frequently used to also describe smoothing, leveling, or altering eternal contours of the bone.

Peri-implantitis: inflammation around dental implant.

Surgical template: A guide used to assist in proper surgical placement and angulations of dental implants.

\section{F. Assumption}

The repeated use and sterilization of the same implant drill will increase the heat generated by that drill with continued use. Dull drills will result in an increase in heat generated compared to new drill.

\section{G. Limitations}

Heat plays an important role in the success of osseointogration of implants. This study will answer new questions of how the age and over use of implant drills at implant site relates to the amount of heat generated by the implant drills during site preparation and how stainless steel and ceramic implant drills compare when evaluating wear and heat produced.

To measure the accurate heat produced at the preparation site . A thermocouple probe was inserted into a prepared receptor site in the bone and temperature recorded. A constant dis- 
tance between the thermocouple canal and the osteotomy site preparation of $0.5 \mathrm{~mm}$ was kept constant.

\section{H. Delimitations}

- A weight of $2.4 \mathrm{Kg}$ was delivered an even amount of force to the handpiece for each trial.

- $\quad$ All preparation preformed by the same clinician.

- Implant drill was activated at speed of 1500 rpms for drilling through the bone.

- $\quad$ Bovine back rib with the same densities was used.

- Depth of the osteotomy was $10 \mathrm{~mm}$ for all trials.

- $\quad$ External Irrigation was used in all bone to be drilled.

- $\quad$ Drills were sterilized as the manufacture recommended after each use

- $\quad 0.5 \mathrm{~mm}$ distance between thermocouple and osteotomy site.

\section{Chapter II: Literature Review}

Successful preparation of an implant site with minimal damage to the bone depends on the temperature generated during surgical drilling. The heat generated at the time of surgery will always cause some degree of necrosis. Thermonecrosis will result as temperature raises. Branemark demonstrated in 1970 that if the temperature of the bone at the osteotomy site was allowed to rise above $47^{\circ} \mathrm{C}$ for more than one minute, bone necrosis would result and the implant would fail to osteointegrate. Studies in the past have looked at many factors in the production of heat during osteotomy preparation including drill speed, cortical thickness, drill sharpness, drill force and drill depth.

"It is critical for the success of endosseous root-form implants that minimal heat is generated in the bone during the drilling of the implant sites. One aspect that has received little em- 
phasis in the literature is the effect of the load placed on the drill during preparation of osteotomies. Temperatures and time were measured while drilling bovine cortical bone at speeds of 1,800 and 2,400 rpm and loads of 1.2 and $2.4 \mathrm{~kg}$. Drilling at a low speed of 1,800 rpm and at a minimal load of $1.2 \mathrm{~kg}$ produced the same heat as when the drill speed was increased to 2,400 rpm and the load was increased to $2.4 \mathrm{~kg}$. Independently increasing either the speed or the load caused an increase in temperature in bone. However, increasing both the speed and the load together allowed for more efficient cutting with no significant increase in temperature.” (Brisman 1996)

According to Harris (2001) in his study, osseous integration of dental implants depends on the use of proper surgical technique during site preparation, including the prevention of thermal injury to the surrounding bone. Heat generation during drilling has been reported to positively correlate with the production of forces at the surgical site. In his study, peak torque and axial load levels were measured during a drilling procedure into a polymeric material simulating the human mandible. Axial rotary milling was performed using 5 different twist drill designs (3i Irrigated Tri-Spade, 3i Disposable, Nobel-Biocare, Straumann, and Lifecore) of 15 to $20 \mathrm{~mm}$ in length and 2 to $2.3 \mathrm{~mm}$ in diameter, at a free-running rotational speed of 1,500 rpm and continuous feed rate of $3.5 \mathrm{~mm} / \mathrm{second}$, to a total depth of $10.5 \mathrm{~mm}$. Ten drills representing each of the 5 types $(n=50)$ were subjected to 30 individual drill “pecks” and heat-sterilized every 3 "pecks” to determine the effects of cyclic mechanical and thermal loading on drill performance. Normal stress and shear stress were calculated from the kinetic data and drill geometries. A drill efficiency coefficient $(\mu)$ was also calculated as the ratio of torsional resistance to translational resistance. Overall, the hypotheses of drill performance dependency on drill type as well as mechanical and thermal accumulated loading were tested and confirmed $(\mathrm{P}<.05)$. He concluded 
that the 5 drill types produced a range of normal stresses (2.54 to $5.00 \mathrm{MPa}$ ), shear stresses (9.69 to $29.71 \mathrm{MPa}$ ), and efficiency (1.16 to 3.16) during repeated testing. Scanning electron microscopic images revealed minor deformations in the cutting edges of the tri-spade drills following testing.

Chacon, Bower, Larsen, McGlumphy, Beck (2006) demonstrate that drill design is important factor in heat generated osteotomy. Temperature was measured with thermocouple technology in vitro using the bovine femoral cortical bone model. Intermittent drilling was accomplished at a constant 2.4-kg load and drill speed of 2,500 rpm. External irrigation at $40 \mathrm{ml} / \mathrm{min}$ with normal saline was used. Three implant drill systems: system A (triple twist drills with a relief angle), system B (triple twist drills without a relief angle), and system C (double twist drills with a relief angle) were evaluated and heat was measured at the final drill in the drilling sequence $(4.0 \mathrm{~mm}$ or $4.2 \mathrm{~mm})$ at a depth of $15 \mathrm{~mm}$. Thermocouples were placed $0.5 \mathrm{~mm}$ from the osteotomy at a depth of $15 \mathrm{~mm}$. Heat measurements were recorded out to 25 uses. Their results showed temperature increased with multiple uses. System A and C drills had temperature measurements that were below $47^{\circ} \mathrm{C}$, even after 25 uses. System B drills had temperatures that exceeded $47^{\circ} \mathrm{C}$ from the initial use. Light microscopy showed little drill wear even after 25 uses. Drill geometry plays a major role in heat production and may explain the increased temperature readings seen in system $B$. These drills lack relief angles and have the smallest clearance angles of the 3 systems. It also has fewer drills in its drilling sequence compared with systems A and C. In conclusion, this study shows that temperatures increase when drills are used multiple times. Systems A and C had acceptable temperature measurements out to 25 uses. System B drills showed significantly higher heat production with little visual signs of wear. 
Cordinli and Majzoub (1997) in their study looked at thermal changes elicited during drilling in site preparation for screw-shaped and cylindrical implants. Heat was measured in vitro in blocks of bovine cortical femur bone. Heat-sensitive thermocouples were placed in the bone specimens at 4- and 8-mm depths and at a constant distance from the periphery of the drilling site; this distance was preset for each type of bur used. Rotary cutting was performed with 10mm-long twist drills (2- and 3-mm diameter) and triflute drills (3.3- and 4-mm diameter) running at 1,500 rpm with external irrigation. A special guide drill was used to ensure unidirectional continuous drilling with a load of 2,000 g. In addition, the effect of irrigation was evaluated during tapping procedures with $10-\mathrm{mm}$-long taps used at $20 \mathrm{rpm}$. The greatest temperature increase was observed with the 2-mm twist drill at both 4- and 8-mm depths. Significantly greater temperature increase was noted at the 8-mm depth versus the 4-mm depth with the twist drills. Such significant difference between temperature rises at the two different drilling depths was not observed with the triflute burs. The time interval required for the maximum temperature reached during rotary cutting to return to baseline values was two times longer for the 2-mm twist drill than for the 3.3-mm triflute bur at both drilling depths. They did not find any significant differences between the maximum temperatures generated when tapping was performed with and without irrigation at both 4- and 8-mm depths. They concluded that the geometry of triflute burs combines cutting efficacy with greater heat dissipation capabilities than twist drills at the drilling depths of 4 and $8 \mathrm{~mm}$ used in their study.

Surgical implant failure is usually detected at or before the second stage surgery. Bone trauma from heat is considered an important cause of this. It has reported that heat production leading to the temperature being raised above $47^{\circ} \mathrm{C}$ for more than 1 min negatively effects living bone. "Drill design, material, and mechanical properties significantly affect cutting efficiency 
and durability. Coolant availability, drill speed and usage were the predominant factors in determining bone temperatures. Implant drills can be used several times without resulting in bone temperatures that are potentially harmful. Continuous drilling in deep osteotomies can produce local temperatures that might be harmful to the bone” (Ercoli and Funkenbusch 2004).

In a study by Abouzgia and James (1995) Temperature was measured during drilling in bovine cortical bone specimens. A surgical drill fitted with a custom-designed speedometer and mounted on a drill press was used to drill holes at one speed, 49,000 rpm, and at forces in the range of 1.5 to $9.0 \mathrm{~N}$. The resulting temperatures were recorded by thermocouples placed at various locations. The distribution of maximum local temperature rise (delta T) was best determined by the function delta $\mathrm{T}=\mathrm{aR}-\mathrm{b}$, where $\mathrm{R}$ is the distance from the center of the drilled hole and $\mathrm{a}$ and $\mathrm{b}$ are constants that were found by regression analysis. It was also found that the temperature increased with force, up to about $4.0 \mathrm{~N}$, and then decreased at forces greater than that because of decreased drilling time. A separate series of tests revealed that temperatures were higher in the longitudinal direction than in the circumferential direction; this difference was attributed to the anisotropic thermal properties of bone.

A study attempt to determine the optimum condition for drilling human cortical bone with a standard twist drill was conducted by orthopedic surgeons Matthews and Hirsch (1972). They stated that temperature measurements have been made in cortical bone while drilling under controlled laboratory conditions. Cortical temperatures greater than 100 degrees centigrade were frequently recorded when drilling if no specific provisions for cooling were made. The force applied to the drill was found to be much more important than drilling speed as a factor in both the magnitude and duration of cortical temperature elevations. Increases in the force applied to the 
drill were associated with decreases in the maximum temperatures and the durations of temperature elevation. A very important finding was that worn drills caused much greater temperature changes than new drills. All forms of irrigation that allowed the stream of irrigating fluid to be directed to the point of penetration of the cortex were effective in limiting the increases in cortical temperature. Tapping did not appear to cause significant temperature elevations.

We know now that forces on drills can increase temperature on bone and cause necrosis. Also, multiple uses of the same drill can raise drilling temperature. It's very important to understand the wear factor and that a sharp drill can be very helpful in reducing the heat. Richart (2000) looked at this factor in his study. He agrees with Matthews and Hirsch that multiple use of dental drills is known to raise drilling temperatures. Therefore, to minimize surgical trauma, well sharpened drills are recommended. In order for him to evaluate surgical trauma due to multiple use, 20 Timedur cannon drills (ZL-Duraplant-Implant-System) were used 51 times in an in vitro experimental setting using pigs' mandibles. Preparations of implant sites were performed with cannon drills at a maximum rotational speed of 1200 r.p.m. with low pressure and water irrigation. Drills were divided randomly into 3 groups and were treated differently after each preparation: 10 cannon drills were cleaned only with distilled water (group 1), 5 cannon drills were disinfected with Secudrill and autoclaved (group 2) and 5 cannon drills were cleaned with Instrument Detergent MIS 027 and autoclaved (group 3). Temperature measurements were performed with a NiCrNi thermocouple placed $0.5 \mathrm{~mm}$ from the drilling site. The width of the cutting edge of the cannon drills was repeatedly examined by scanning electron microscope (SEM). His results revealed that temperatures measured at all times were below the bone injuring level. Drills reused more than 40 times stood out with an increased number of higher temperatures. Only autoclaved drills showed an increased width of the cutting edges. 
Types and variation in irrigation has been studied by only a few investigators. Komatsu and Yoshiaki (1992) did a studied the distribution of heat to bones and the maximum temperature that developed when cutting bone with drills. Generation of heat that spread in the presence or absence of irrigation when drilling with IMZ, Branemark, and ITI implant (F type) drills was observed in the pig rib via thermography. Without irrigation, the condition of heat spread in each drill and bur differed according to bur shape and drilling site. They found that maximum heat temperature without irrigation was higher than that with irrigation for any IMZ, ITI, and Branemark drill.

Drill wear plays an important role in generating heat during a surgery, the increase number of drill uses will cause the temperature to raise. A study conducted by Scarano, Carinici, Quaranta, Assenza and Piattelli (2007) measured the temperature changes in cortical bone and marrow spaces during implant site preparation in bovine rib bone. They concluded that there was an higher and statistically significant increase in the temperature in the cortical bone; this increase in temperature increases with the number of the times of drill use. The drill wear seemed to play a major role in heat production and could explain the observed increased temperature of the bone.

Chhabara, Westerlund, Kline and Mclaughin (2005) stated in their study that osteopetrosis is principally related to the characteristic brittle marble bone in which fractures may be easily induced by relatively low-energy mechanisms. Femoral fractures are common in their patient population, and management presents a unique technical challenge. While osteopetrotic bone may be penetrated with a drill bit, the drill bit flutes are immediately filled with bone. This rend- 
ers the drill ineffective, and generation of significant frictional heat can result in breakage of the drill.

Davidson and James (2003) agree that speed and diameter are very important factors in heat generation. They used thermo-mechanical equations from machining theory to predict heat generation due to drilling and were coupled with a heat transfer FEM simulation to predict the temperature rise and thermal injury in bone during a drilling operation. The rotational speed, feed rate, drill geometry and bone material properties were varied in a parametric analysis to determine the importance of each on temperature rise and therefore on thermal damage. It was found that drill speed, feed rate and drill diameter had the most significant thermal impact while changes in drill helix angle, point angle and bone thermal properties had relatively little effect. Eriksson and Adell stated in their study that all temperatures recorded were below the level for impaired bone regeneration. It was concluded that drilling according to the osseointegration technique does not cause any impaired bone regeneration because of excessive heat production.

An experiment was conducted by Hobkirk and Rusiniak (1977) to investigate the pressures that are exerted on drills during the preparation of bone involved twenty operators using six different types of drills at high and low speeds to prepare standardized holes and slots in animal bone. The peak vertical forces exerted varied between 5.98 and 24.32 newtons $(x=12.45$ newtons). The mean vertical forces varied between 4.22 and 18.93 newtons ( $\mathrm{x}=9.16$ newtons). Spear point and twist drills were associated with significantly lower operating pressures and shorter operating times than round and fissure burs. They stated that the differences were much less than the interoperator variations. 
Lavelle and Wedgwood (1980) looked at the same factor as Kotmatsu and Yoshiaki. They concluded that frictional heat generated during bone drilling was reduced by internal irrigation compared with external or no irrigation. This was based on an in vitro study using two bur designs at low rotational speeds to prepare experimental cavities to varying depths. Watanabe, Tawada, Komatsu and Hata agree with both previous studies and concluded that maximum heat temperature without irrigation was higher than that with irrigation for any drill. Okada and Watanabee investigated the repeated use of IMZ implant drill system to know the service life of IMZ drills. Repeated drilling tests were done for spiral and cannon drills using pig thighbone under 450gf static load. As a result, the following conclusions were obtained. 1 . On the spiral drill, drilling time was extended after every drilling and drilling became impractical after the twenty seventh time drilling. 2. The edge of the spiral drill was worn out after twenty seven times' repeated drilling. 3. Difference in drilling time with cannon drill was not recognized up to fifty times' repeated drilling. 4. The edge of cannon drill did not wear out. Drill wear is as much important factor as the drill speed, design, irrigation and diameter stated in the past literature review.

\section{Chapter III: Materials and Methods}

\section{A. Equipment}

$>2$ Different Implant drill systems made by different companies (ZIMMER and THOMMEN).

Digital Caliper model number 30006.

$>$ Guiding Template.

> Daq personal 3000 series by IOtech.

$>$ Daq View data acquisition program.

$>1$ Thermocouple model number (5TC-TT-J-24-36) by OMEGA. 
5-7 Bovine back ribs with the same densities.

$>1$ implant hand piece and motor.

Digital weight scale.

$>$ External irrigation $40 \mathrm{ml} / \mathrm{min}$.

$>$ Sterilization.

\section{B. Methodology}

\section{i. Software (Data acquisition) setup:}

DaqView is a 32-bit Windows-based data acquisition program that can be used to operate Personal Daq/3000 Series devices. DaqView allow to:

$>$ Set up system parameters (select channels, gains, transducer types, etc) to acquire data.

$>$ Save data to disk and transmit data to spreadsheets and databases.

Automatically re-arm the trigger function and save data in new files as needed.

Configure the counter/timer into one of three modes for measuring frequency, totalizing, or generating pulse trains.

$>$ Display digital I/O

A very important and time consuming part of the research is setting up the experiment. For future research opportunity, a detailed description of the hard and software setup is described below. The first step is to install the DaqView software. After the installation complete connect the hardware and follow the screen instruction to complete installation. Open the DaqView software (Figure 1). 
Figure 1. DaqView software

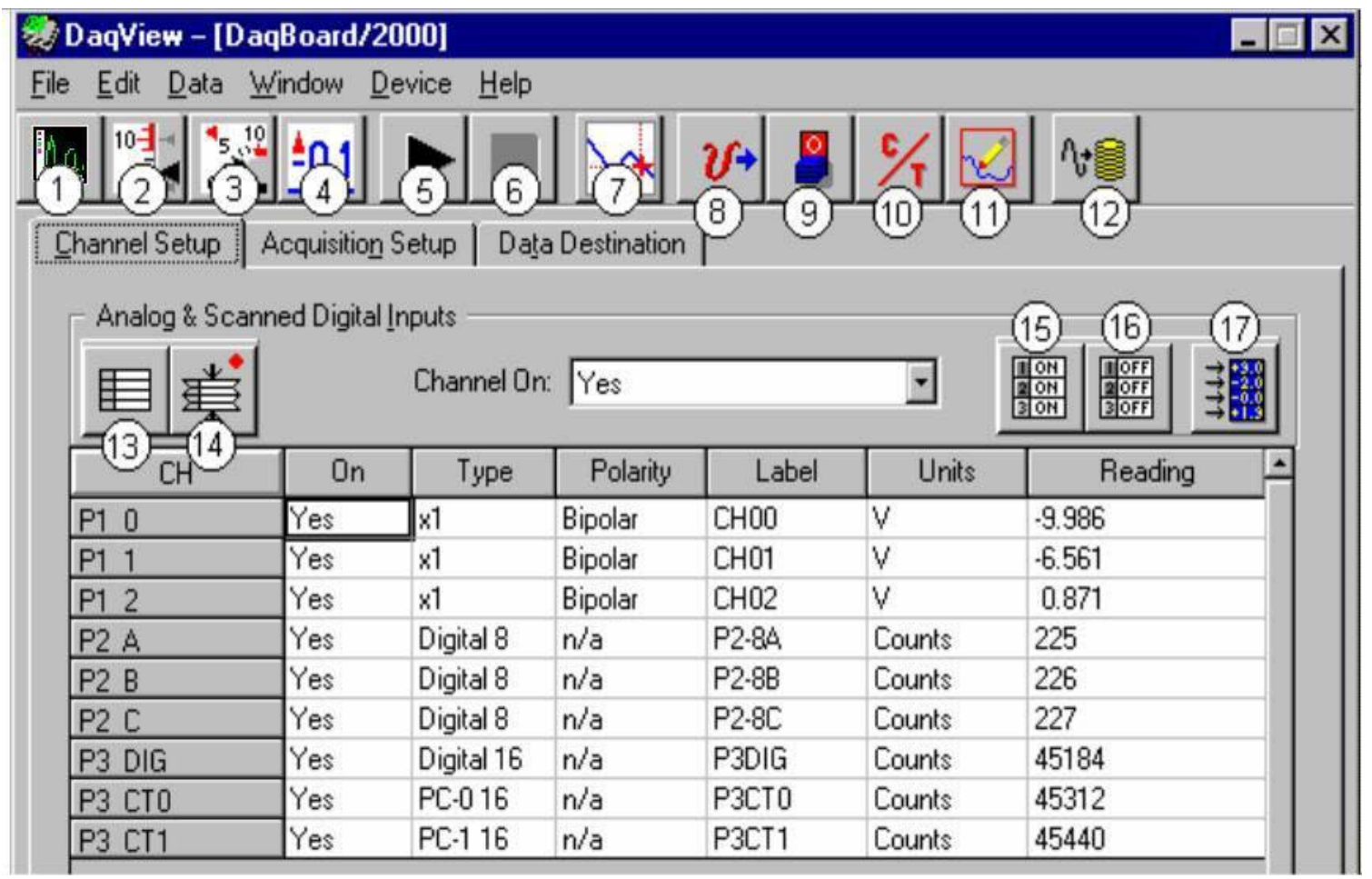

Source: DaqView and ViewXL IOtech User's Guide.

1

2

3

4

5

6
Scope

Bar Graph Meters

Analog Meters

Digital Meters

Start All Indicators

Stop All Indicators
Brings up a window from which Scope and/or Chart displays can be configured and used for analyzing data in relation to $\mathrm{x}$ and $\mathrm{y}$ axes.

Displays a bar graph meter.

Displays an analog dial meter.

Displays a digital meter. Starts displaying data in the Reading column and any open Chart or Meters window.

Stops displaying data in the Reading column and any open Chart or Meters window. 
7

8

9

10

11

12

13

14

15

16

17
View File Data

Analog Output

Digital I/O

Counter/Timer

Waveform \& Pattern

Output

Acquire

Show ALL Channels

Hide INACTIVE Channels

Turn All Visible Channels ON

Turn All Channels OFF

Channel Reading
Launches an independent

post-data acquisition

program.

Displays the Analog

Output window of the available DAC channels. Displays the Digital I/O window.

Displays the Counter/Timer window. Displays the Arbitrary Waveform and Streamed Output windows. Activates an acquisition of data to a file.

Expands Analog \& Scanned Digital Inputs spreadsheet to show all channels, whether active or not.

Condenses the Analog \& Scanned Digital Inputs spreadsheet, to hide channels that are inactive. Turns all visible channels ON. Hidden channels will remain off. Turns all the channels OFF.

A toggle button that enables [or disables] the Channel Reading column of the Analog and Scanned Digital Input spreadsheet.

\section{ii. Channel setup:}

The Channel Setup window displays the analog and scanned digital input channels and allows you to configure them. Each row shows a single channel and its configuration (Figure2). The number of rows may vary, but each row has seven columns. Some columns allow blocks of 
cells to be altered at the same time (clicking a column header can select the entire column). Other columns allow only a single cell to change For the purpose of this research the channel setup choosen are summarized below.

Figure 2. Channel setup tab

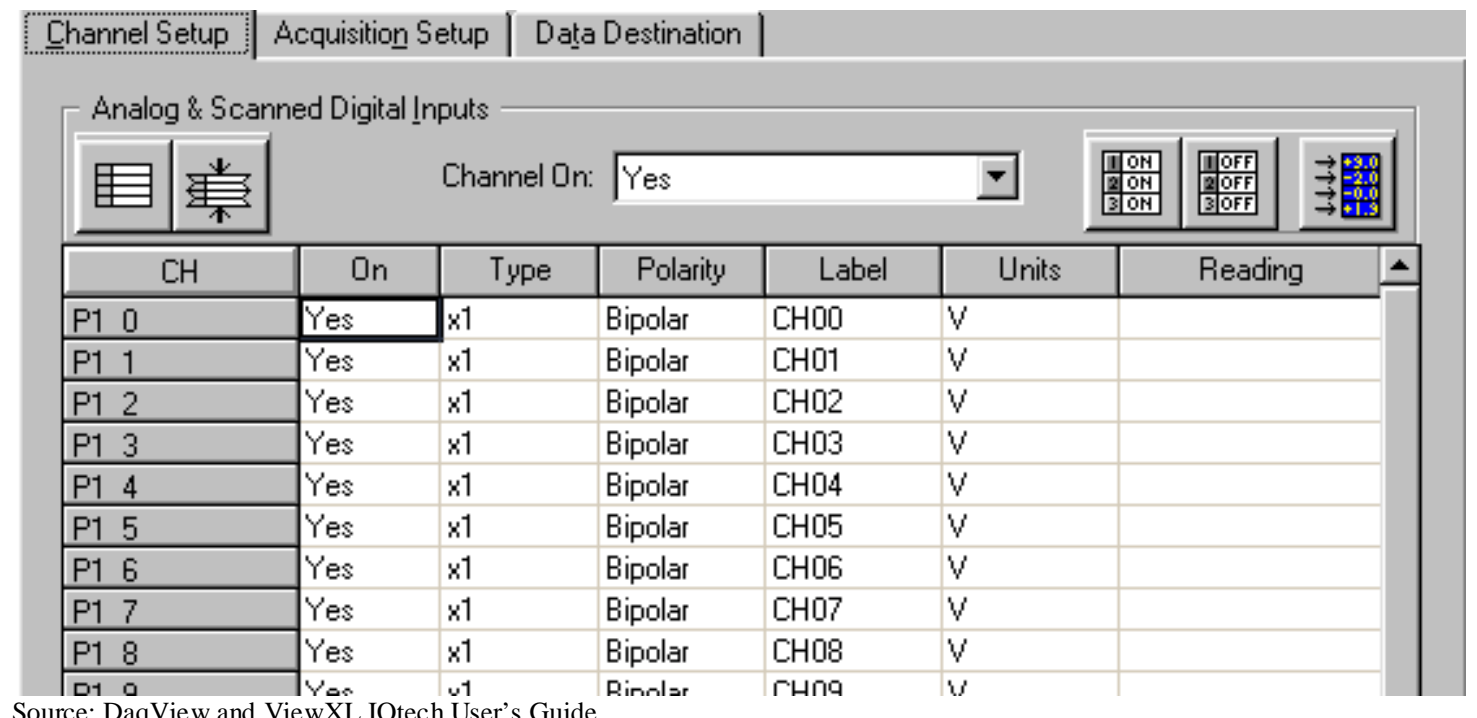

CH

On
The channel number (cannot be changed from this window). This number includes the main channel number and the expansion board number and channel.

This column allows you to select whether data will be collected from that channel. When a cell or block of cells in this column is selected, a selection box will appear that allows "Yes" to enable or "No" to disable the channel. Double-clicking a cell in this column will toggle the channel status. The Edit menu allows you to Make All Channels Active or Make All Channels Inactive. 
Type

Polarity

Label

Units

Reading
This column allows you to set the gain or input type for each channel. The gains and types will vary among the option cards. A block of cells in this column can be selected for multiple channels with the same type of option card. Double-clicking a cell will select the next available gain or type. J type was chosen to corresponds with Thermocouple type used for this research. Using Daqveiw 3000 series, this column is pre set in the Hardware Setup window. For selected cells that can be changed, a selection box will display "Unipolar” or "Bipolar”. Doubleclicking in a cell will toggle the polarity. If the hardware cannot program the polarity, no selection box will be displayed.

This column contains a descriptive name for the input channel. The default label is the channel number. The channel \# chosen was 01

When a Units-cell [or block of cells] is highlighted, unit options can be selected from a pull-down box:

o Temperature: ${ }^{\circ} \mathrm{C}$ was chosen for this research.

This column displays the device's analog or scanned digital input readings. This column cannot be altered by the user and is enabled by selecting Enable Input Reading Column under the Data menu or by selecting "Start/Stop All Indicators" under the window menu. This column will update the readings as fast as the computer will allow. The spreadsheet cannot be altered while the input reading column is enabled. 


\section{iii. Acquisition Setup:}

Selecting the second tab of the main window displays the Acquisition Setup window. As showing in figure 3, the four main parts of this window include setup parameters for triggering and configuring the scan. These settings will be used when an acquisition to disk is started by selecting “Acquire” (last item on the toolbar). When the trigger is satisfied, the scans are collected at the selected scan frequency and stored to disk in the designated file.

\section{Figure 3. Acquisition setup}

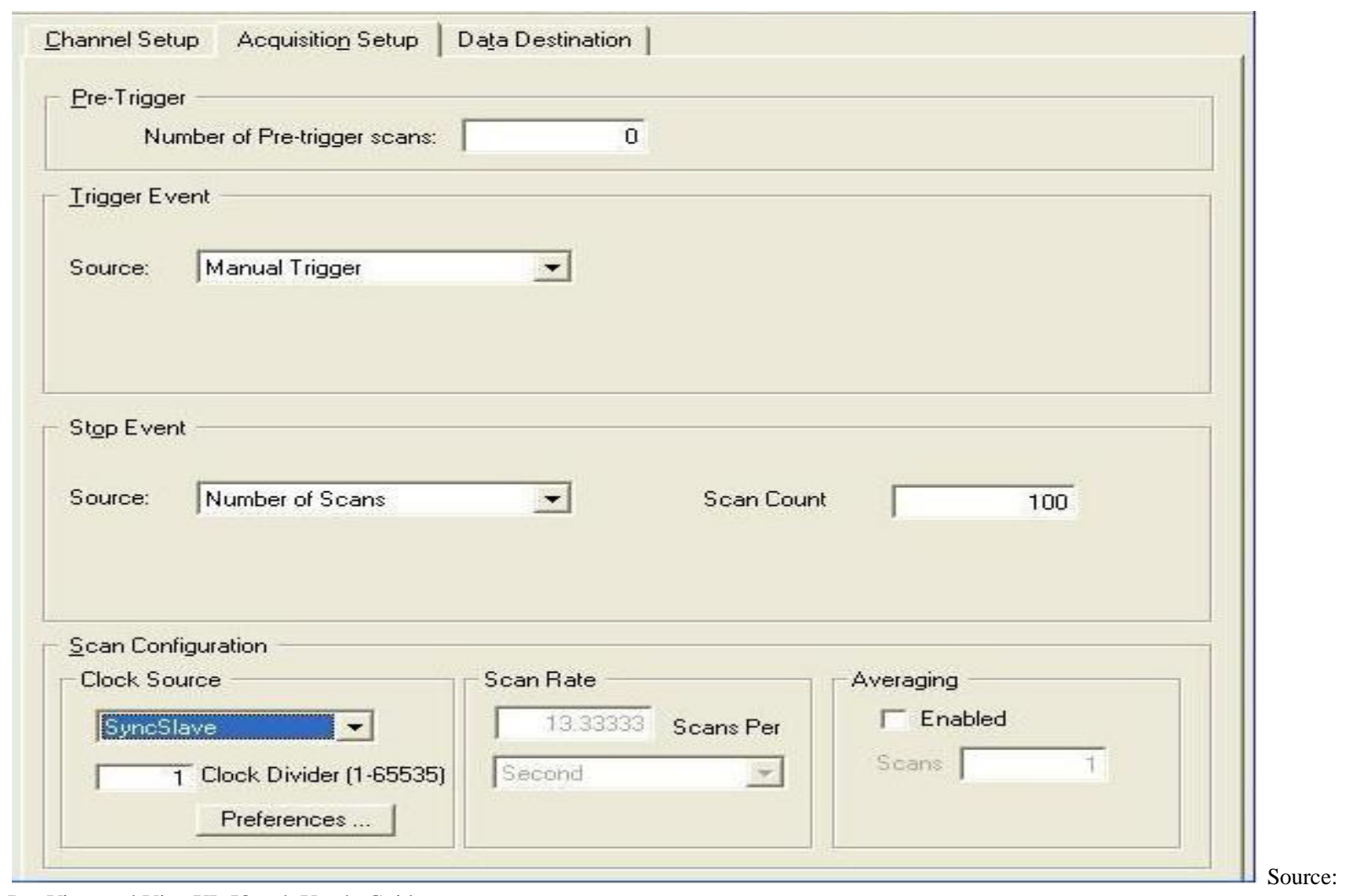

DaqView and ViewXL IOtech User’s Guide.

The data acquisition was set as a manual trigger for this research. It was asked to be stop scanning after 15 scans. 1 scan per second for a total of 15 scan for the each osteotomy preparation. Clock source was internal recording and scan rate was 1 scan per second. 


\section{iv. Data Destination:}

Selecting the third tab of the main window displays the Data Destination window(Figure 4). The two parts of this window let you designate the directory for acquired data and the desired file formats.

\section{Figure 4. Data setup tab}

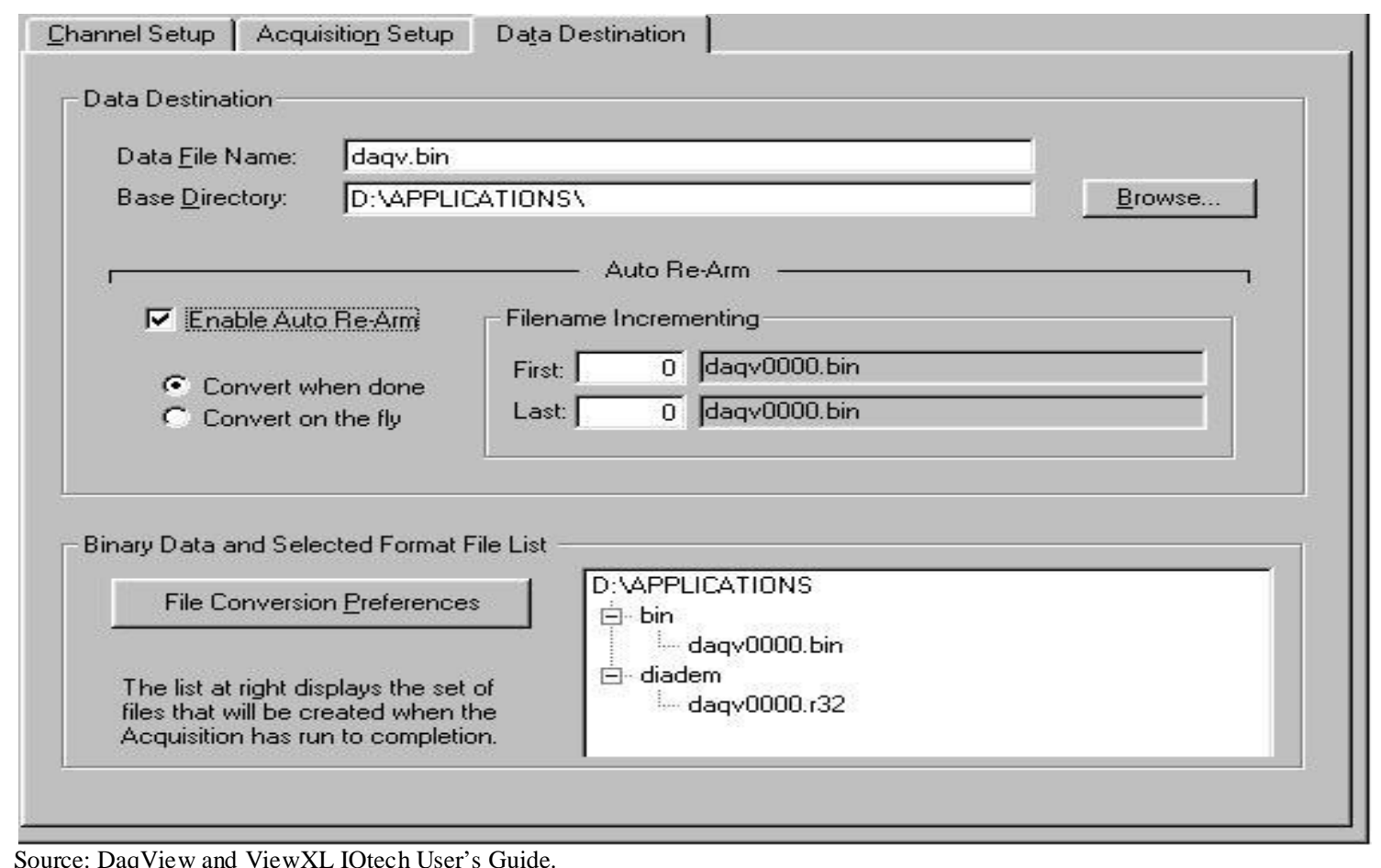

Acquired data saved the file name (any data file name selected by the operator). This file name always ends with "bin” extension. The designated file was saved to computer hard drive by the browse button. With the enable Auto re-arm box checked. I can specify when the file conversions are preformed and the sequence range of incrementing file name. The file conversion preference was set to select the format to be saved as ASCII text. 


\section{v. Hardware setup:}

Open up the configure system hard ware and choose the for the A/D signal Reference to be differential not a single end. For the 300 series and the $\mathrm{j}$ thermocouple the differential A/D signal reference work accurately for the purpose of this research (Figure 5)

\section{Figure 5. System hardware setup window}

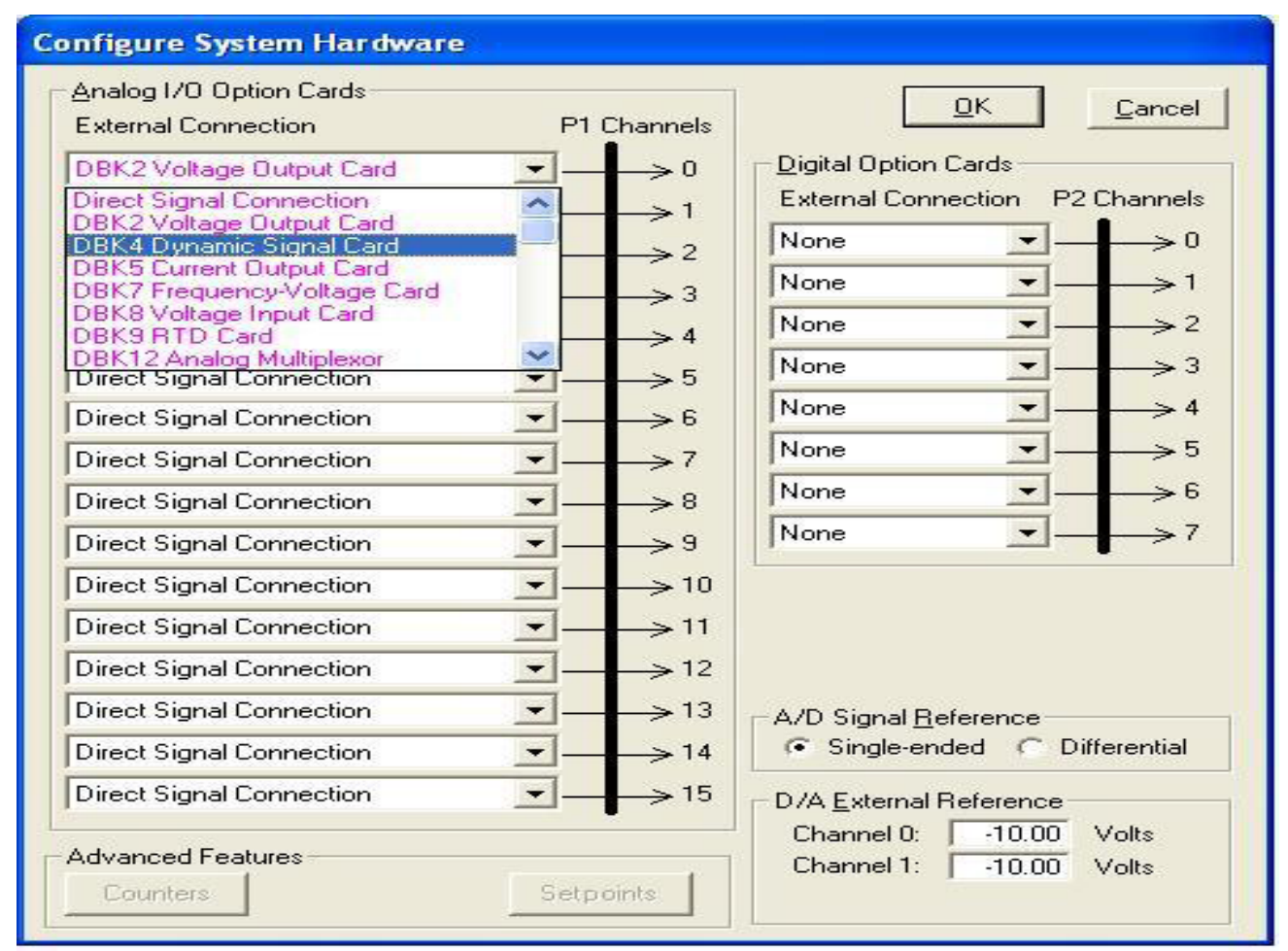

Source: DaqView and ViewXL IOtech User's Guide.

The hardware can be connected with the thermocouple (5TC-TT-J-24-36) at one end to the designated channel while the other end is measuring the temperature in C. Selecting the Digital Meters icon brings up the Digital Meters window to display several channels in numeric format. To activate the display, $<$ Start $>$ button on the left side of the toolbar was selected. The number of channels displayed can be vary by selecting the input box at the end of the toolbar (figure 6) 


\section{Figure 6. Digital meter widow}

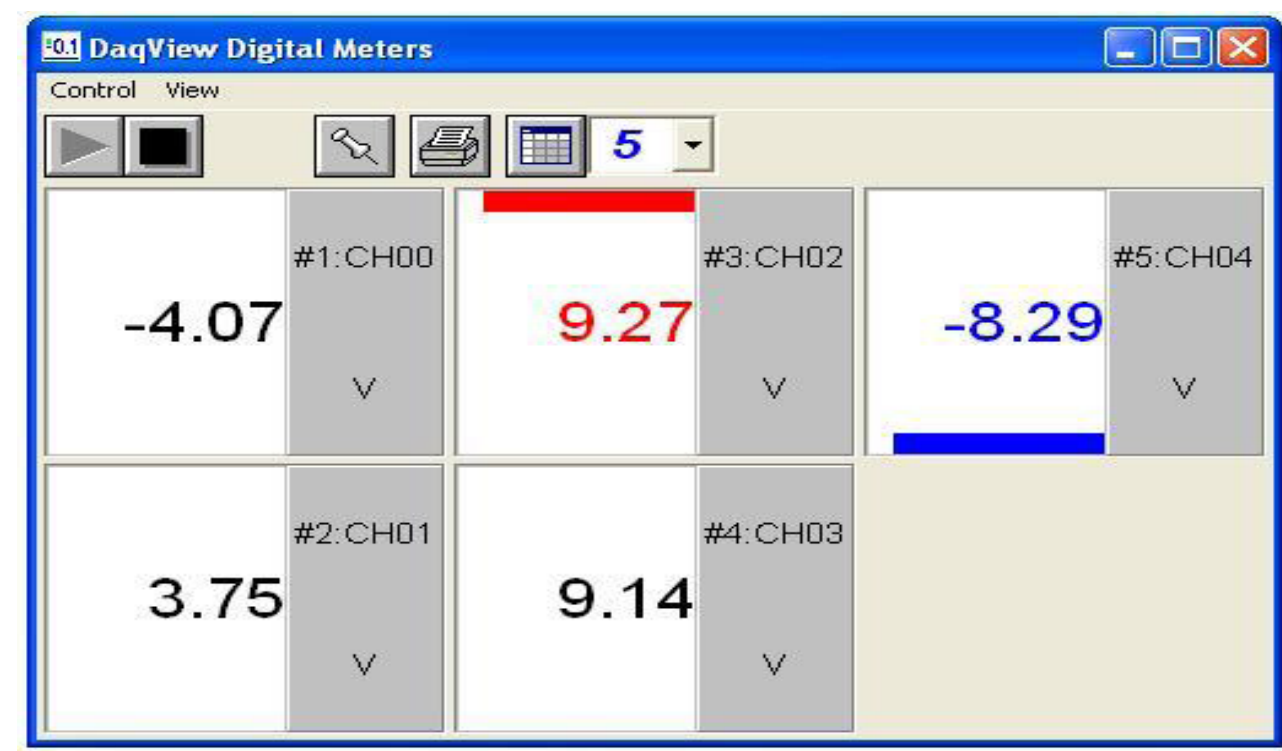

\begin{tabular}{|l|}
\hline Select Channel... \\
\hline Set Scale... \\
\hline Show Trend Indicator \\
\hline Set Limits... \\
$\checkmark$ Show Limits \\
\hline Properties... \\
\hline
\end{tabular}

Source: DaqView and ViewXL IOtech User’s Guide.

\section{vi. Scanning Electron Microscopy (SEM):}

It is the hypothesis of the investigators that implant drilling systems will generate more heat as the drill becomes worn through multiple uses. To aid in the detection of the wear of the drilling systems, Scanning Electron Microscope (SEM) images of the drilling systems are used to compare the image of a new, unused drilling system and that of a drilling system used 25 times. This was completed, with the aid of Liviu Magean and Adrienne McGraw of the West Virginia University Chemical Engineering Department, using a Hitachi S-4700 SEM.

\section{SEM Principles}

SEM works through an electron beam that is targeted towards the sample specimen. The electrons are generated from a tungsten tip, then collimated as a beam towards the sample resulting in three possible outcomes; passage through the sample resulting in an electron cloud, reaction with electrons of the sample, resulting in an excited state with their subsequent emission oc- 
curring during the return to the stable state, or electrons deflected off the nucleus of the sample and emitting x-rays. The passage of electrons through the sample resulting in an electron cloud is the result of a sample with a non-conductive surface. The reaction with the nucleus and excitation of electrons is picked up by the EDX detector to produce an image and give elemental information related to the sample. Since the purpose of this investigation was not the elemental information of the drilling system, the EDX detector was not used for the samples. Rather, an upper and lower snorkel detector was to obtain the image.

As stated, the sample must have a conductive surface or the electron beam will pass through the sample and generate an electron cloud. If this occurs, the image produced will be that of the top side of the SEM chamber not that of the sample. The ceramic drilling system requires a coating to produce a conductive layer. The coating placed was that of a Gold-Palladium mixture for 20 seconds resulting in a layer roughly 60-90 Angstroms. It is key to produce a thin layer so that the electron beam will interact with the sample and not a thick conductive coating. The Hitachi S-4700 will magnify images up to 250,000x, however, for the purpose of the study a magnification of 500x was used.

\section{Scanning Process:}

Each drilling sample was placed on the sample stage using a gloved hand and cotton pickups. The samples were adhered to the sample stage with double sided carbon tape. Nonconductive samples were then taken to the coating apparatus and placed under a vacuum and flushed with Argon to get to a specific pressure for each coating. For this experiment, the coating used was Gold-Palladium that required an Argon flush to the pressure of 80 millitorr. The coating was applied for 20 seconds, resulting in a thin coating layer of approximately 60-90 
Angstroms. Once coating was completed for the non-conductive samples, the sample on the sample stage was taken to the SEM and placed into the chamber. The conductive samples were taken to the SEM immediately after placement on the sample stage. Once a sample was placed into the SEM chamber, the sample was moved into position of the upper and lower detectors to obtain the desired images of the drilling tip and shaft at magnifications of 20X, 200X, and 500X. Images were analyzed on the computer screen for quality and then were saved onto an external hard drive. Vacuum pressure within the chamber was then released, followed by opening of the chamber door. The sample on the sample stage was removed from the SEM chamber. The sample was then removed from the sample stage and placed back into its respective container. The samples containing the Gold-Palladium coating were then taken and placed into a methanol ultrasonic bath to remove the Gold-Palladium coating. This process was repeated once the drilling systems were used on the bovine bone.

\section{vii. Preparation methodology:}

Two implant drill systems were evaluated in vitro using bovine back rib bone. The choice of this type of bone was based on the finding of Eriksson and Adell (1986), who found that the density and the relationship between cortical and cancellous bone are similar in bovine ribs and human mandibular bone. Transverse sections of $12 \mathrm{~mm}$ long were obtained and stored at -20 C. To minimize changes in their mechanical and thermophysical properties, the specimens were kept frozen in saline at -20 until their use within 3 to 4 week. This procedure was based on the finding of Seldin and Hirich(1966), who found no significant changes in bone’s physical properties when it was frozen up to 4 weeks. The bovine bone was defrosted to room temperature before use. Using a pre measured template one canal 10mm long was drilled for the thermocouple 
using a round bur. Two marks using a sharp pencil were made next to the thermocouple canal and $0.5 \mathrm{~mm}$ away from the largest final size drill at each side. One of these marks be used for the stainless steel drill and the second mark used for the ceramic drill (Figure 7). The template was taken off. The distance was confirmed using CMT digital caliper model 30006. Thermocouple model was inserted in to the canal to the $10 \mathrm{~mm}$ depth. To insure isolation of the thermocouple from the external environment wax was applied to the external canal opening. A wood wedge was applied to keep the thermocouple in position. The thermocouple was connected to the personal dag/3000 series model 1136-0901 IQtech for data collection and temperature recording. A pilot trial was preformed ensuring thermocouple ability to record different temperature. The thermocouple and the osteotomy site were all equal distance from each others. The bone blocks were immersed in a Saline bath. This system allows a control baseline bone temperature which was set at 24C. Using a digital scale the bone block was positioned on the scale hand held and the weight was set to zero. When the specimen reached the base temperature of $24^{\circ} \mathrm{C}$. The specimen was ready for the osteotomy. Two implant drill system were used. System A was stainless steel surgical drills sizes 2.3, 2.8 and 3.4 mmD (Tapered screw- vent surgical drills by Zimmer dental). Systen B was alumina-toughened zirconia ceramic surgical drills Sizes were 2.0, 2.8 and 3.5mmD ( Thomman Medical). Both implant drill systems were made for multiuse. Sterilization before the first time use and after each osteotomy was preformed. Sterilization was done using Amsco Vacamatic Autoclave eagle series \# 3043. Drills were autoclaved at 130C for 40 minutes. Sterilization was done with 5 minutes kill time cycle and 35 minutes dry cycle. Using the initial mark $0.5 \mathrm{~mm}$ from the thermocouple system A was used (Zimmar Dental). Sequential drilling was preformed and maximum temperatures were recorded for all the three drills used for the first system. System A started with 2.3, 2.8 and 3.4 mmD. Speed of 1500 Rpm and external irrigation 
40ml/sec were used. As the hand piece speed of 1500 Rpm was achieved the preparation preformed at the osteotomy site. Maintaining a constant weight of $2.4 \mathrm{~kg}$ applied to the hand piece while drilling. A constant weight was assured by using the digital weight scale. Keeping the pressure and load apply to $2.4 \mathrm{~kg}$ during the whole osteotomy preparation. After each trial the drills were sterilized and the preparation repeated twenty five times for each system as manufactured recommended as the age of the multiuse drill. The same methods previously described were followed for system B. The maximum temperatures were recorded for twenty five preparations with sterilization after each use. All the ostetomies were performed by the same clinician to simulate a real clinical setting situation. After twenty five times of usage. A total of fifty osteotomies. Both implant drills system were Scanned using Scanning Electron Microscopy for final analysis.

Figure 7. Template. Distance between thermocouple and drills

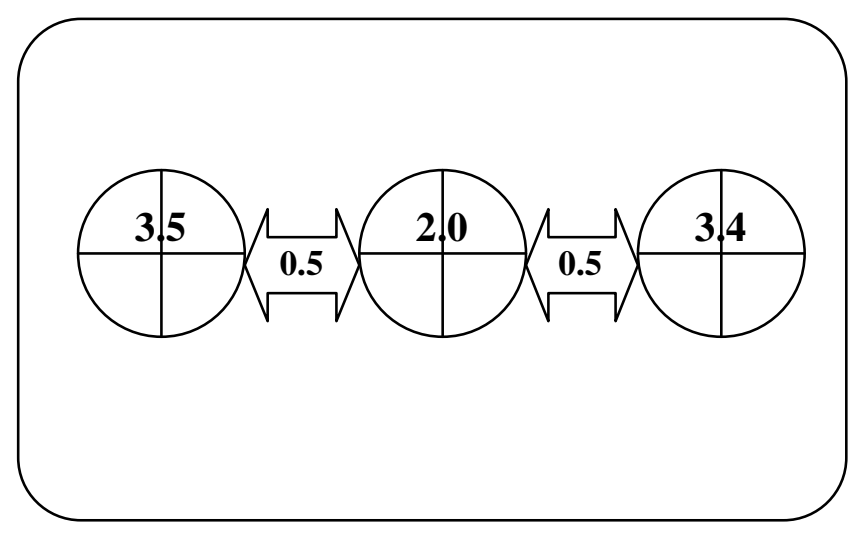

\section{Budget}

2 Thermocouple w/ probe packages (5TC-TT-J-24-36).

Sterile saline. 
Lab materials $\$ 100$

Bovine bone $\$ 50$

3 Zimmer stainless steel drills Donated

3 Thommna ceramic drills Donated

Scaning Electron Microscoby (Lab time 5hr). $\$ 360$

Zimmer motor unit. Borrowed Total expenses $\$ 600$

\section{Chapter IV: Result and Discussion}

\section{Result:}

The present study provides information on the performance of multiuse drill type during repeated usage and sterilization. The number of drill uses result in an increase heat generated by that drill. Drill function is dependent on the drill sharpness and material. Different drills made by different companies react differently. Repeated drilling and sterilization did alter the cutting ability of all drill types and the amount of heat produced by that drill.

Manufacturer’s recommendations are 25 uses for each drill. 25 trials were completed for each drilling system for a total of 50 trials. Sequential drilling was used for both systems. System (A) drill sizes were 2.3, 2.8 and 3.4mmD. System (B) drill sizes were used 2.0, 2.8 and 3.5mmD. Initial bovine base temperature was $24^{\circ} \mathrm{C}$. Three readings were taken for each trial osteotomy and each drilling system. The maximum temperature was recorded for each drill and for both systems. Each trial's readings were then averaged and graphed. The graph below shows an upward trend for each drilling system (figure 8 and 9), indicating an increase in heat production with repeated use of drills. Stainless drill system values ranged from $25.03-31.13^{\circ} \mathrm{C}$. Ceramic 
drill system values ranged from $25 \cdot 0-31.2^{\circ} \mathrm{C}$ (Tabel 1). No significant different were found between the two systems. Stainless steel and ceramic drills responded similarly to wear and both generated more heat as the drills wear used (figure 8). The maximum temperature for system (A) was $31.3^{\circ} \mathrm{C}$ and $31.2^{\circ} \mathrm{C}$ for system (B). It must be taken into consideration that the beginning temperature of the bovine bone began lower than that of normal body temperature. With a $7^{\circ} \mathrm{C}$ increase for beginning temperatures (body temperature) in vivo, increase of this magnitude should remain below the limit of $47^{\circ} \mathrm{C}$, the accepted limit to prevent osteonecrosis. Results indicate there was no significant difference in temperature generated between each drilling system. Furthermore each drilling system increases heat production with increased usage and wear.

Figure 8. Heat generated with Stainless steel VS. Ceramic

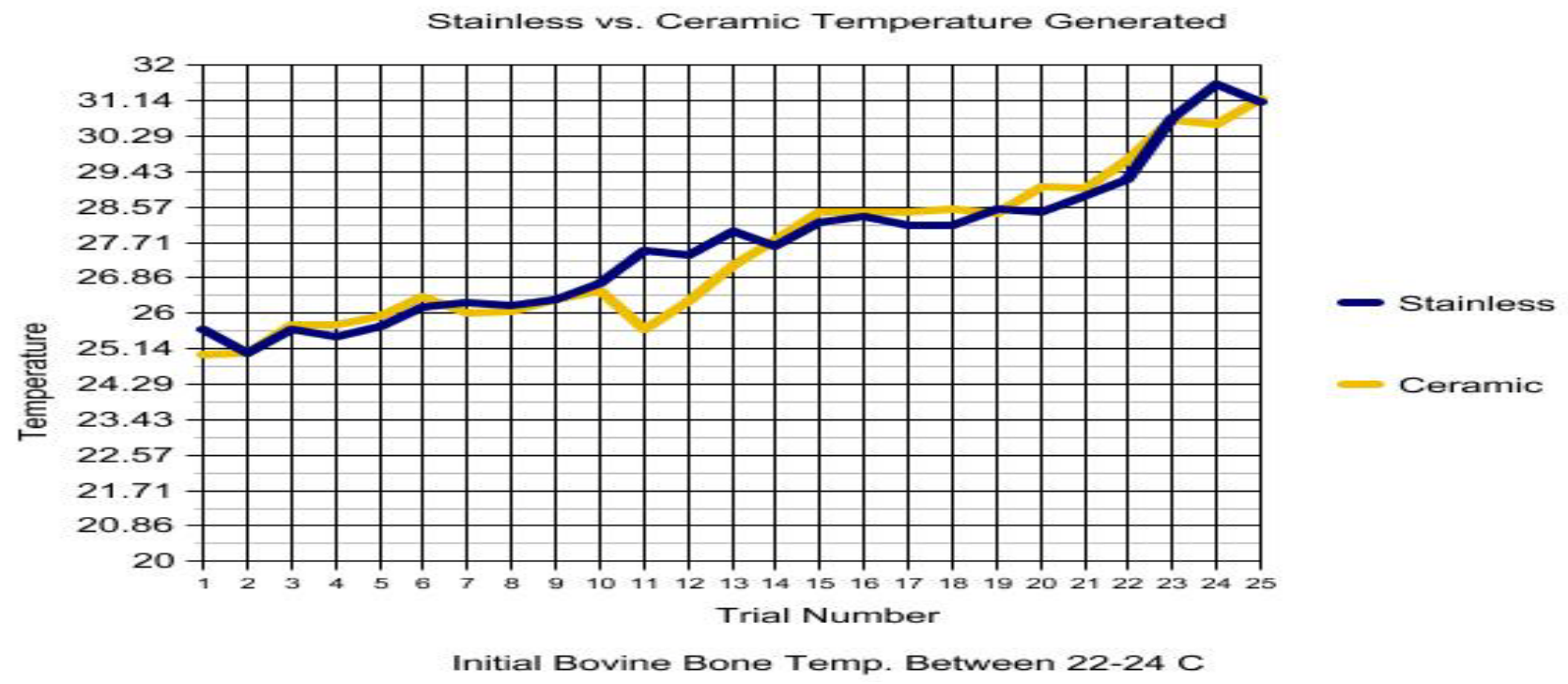


Figure 9. Heat generated with all six drills (3 Stainless steel VS. 3 Ceramic)

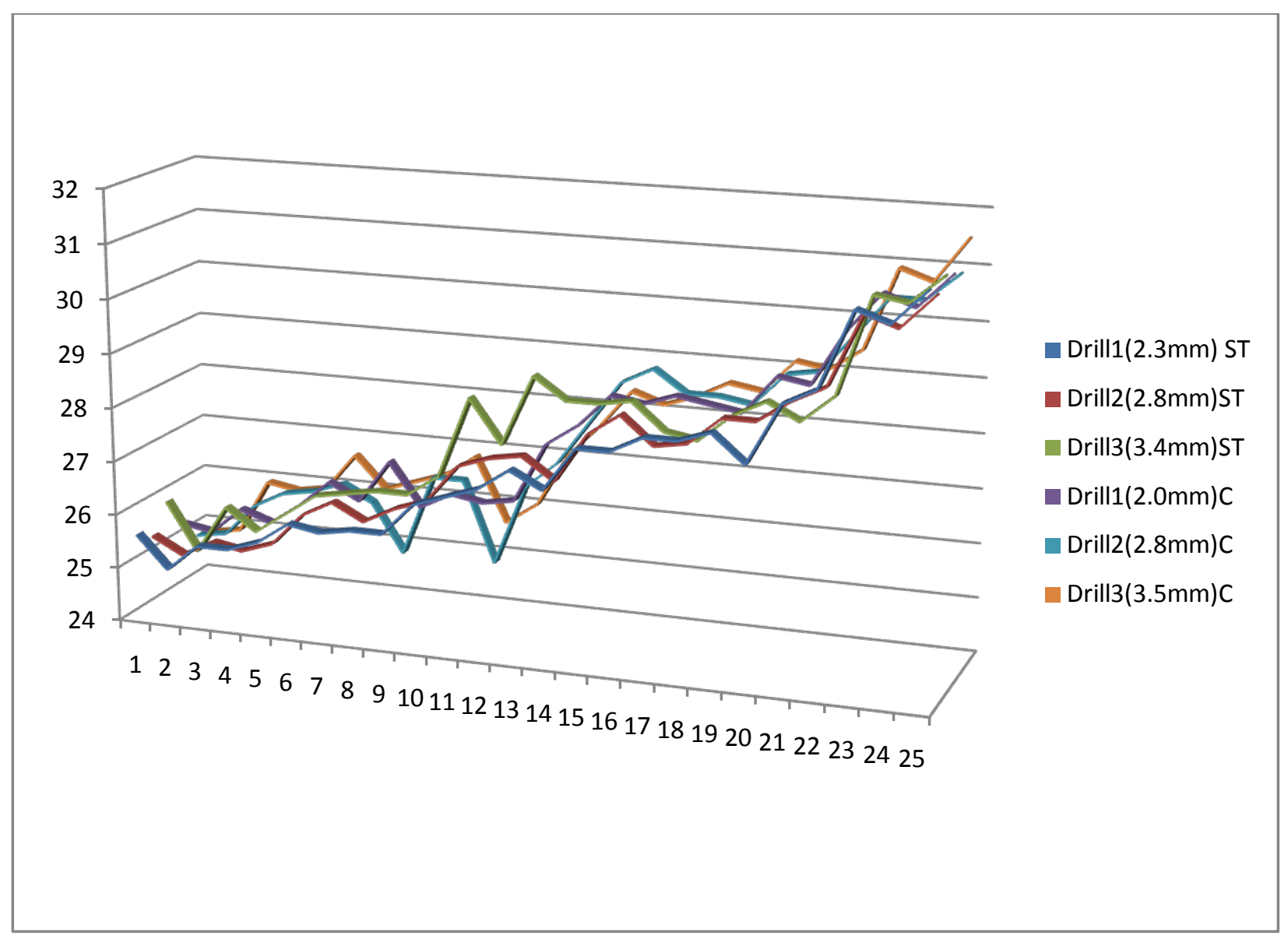


Table 1. Maximum heat recorded for each drill. (ST: steel, C: ceramic)

\begin{tabular}{|c|c|c|c|c|c|c|}
\hline $\begin{array}{l}\text { \# of } \\
\text { trial }\end{array}$ & $\begin{array}{l}\text { Drill1(2.3m } \\
\text { m) ST }\end{array}$ & $\begin{array}{l}\text { Drill2(2.8mm) } \\
\text { ST }\end{array}$ & $\begin{array}{l}\text { Drill3(3.4mm) } \\
\text { ST }\end{array}$ & $\begin{array}{l}\text { Drill1(2.0mm } \\
\text { )C }\end{array}$ & $\begin{array}{l}\text { Drill2(2.8mm } \\
\text { )C }\end{array}$ & $\begin{array}{l}\text { Drill3(3.5mm } \\
\text { )C }\end{array}$ \\
\hline 1 & 25.6 & 25.4 & 25.9 & 25.3 & 24.9 & 24.8 \\
\hline 2 & 25 & 25.1 & 25 & 25.2 & 25 & 24.9 \\
\hline 3 & 25.5 & 25.4 & 25.9 & 25.7 & 25.6 & 25.9 \\
\hline 4 & 25.5 & 25.3 & 25.5 & 25.5 & 25.9 & 25.8 \\
\hline 5 & 25.7 & 25.5 & 25.9 & 25.9 & 26 & 25.9 \\
\hline 6 & 26.1 & 26.1 & 26.3 & 26.4 & 26.2 & 26.6 \\
\hline 7 & 26 & 26.4 & 26.4 & 26.1 & 25.9 & 26 \\
\hline 8 & 26.1 & 26.1 & 26.5 & 26.9 & 25 & 26.2 \\
\hline 9 & 26.1 & 26.4 & 26.5 & 26.1 & 26.5 & 26.4 \\
\hline 10 & 26.7 & 26.6 & 26.9 & 26.4 & 26.5 & 26.8 \\
\hline 11 & 26.9 & 27.3 & 28.4 & 26.3 & 25 & 25.6 \\
\hline 12 & 27.1 & 27.5 & 27.6 & 26.4 & 26.5 & 26 \\
\hline 13 & 27.5 & 27.6 & 28.9 & 27.5 & 27 & 27 \\
\hline 14 & 27.2 & 27.2 & 28.5 & 27.9 & 27.8 & 27.6 \\
\hline 15 & 28 & 28.1 & 28.5 & 28.5 & 28.6 & 28.3 \\
\hline 16 & 28 & 28.5 & 28.6 & 28.4 & 28.9 & 28.1 \\
\hline 17 & 28.3 & 28 & 28.1 & 28.6 & 28.5 & 28.3 \\
\hline 18 & 28.3 & 28.1 & 28 & 28.5 & 28.5 & 28.6 \\
\hline 19 & 28.5 & 28.6 & 28.5 & 28.4 & 28.4 & 28.5 \\
\hline 20 & 28 & 28.6 & 28.8 & 29.1 & 29 & 29.1 \\
\hline 21 & 29.1 & 29 & 28.5 & 29 & 29.1 & 29 \\
\hline 22 & 29.4 & 29.3 & 29 & 30 & 29.8 & 29.4 \\
\hline 23 & 30.8 & 30.6 & 30.8 & 30.7 & 30.5 & 30.9 \\
\hline 24 & 30.6 & 30.4 & 30.7 & 30.5 & 30.5 & 30.7 \\
\hline 25 & 31.2 & 31 & 31.2 & 31.1 & 31 & 31.5 \\
\hline
\end{tabular}

\section{Discussion:}

A variety of drilling materials have been used as stated by Albrektsson T (1985) for heat studies: rabbit mandible, pig maxilla and mandible, bovine block cortical/medullary bone, polymeric material, porcine ribs, and bovine cortical bone. It has been reported that as bone density increases, temperature also increases by Eriksson R, Albrektsson (1984) in this study, bovine 
back ribs bone were used to closely approximate the human mandible. Back ribs bovine bone and human mandible have the same cortical and concellous bone ratio stated by Harish (1986). Eriksson R, Albrektsson(1983) previously reported, increased heat production caused by worn drills may result in excessive heat and primary failure to achieve osseointegration. Surgical trauma is significantly reduced with the use of well-sharpened drills run at moderate speed under flowing saline cooling. The results of this study support the finding of Eriksson (1983). As drill uses increases, temperature also increases. Interestingly, there was wear noted visually after 25 uses for both systems A and B. After 25 uses, systems A and B continued to maintain drilling temperature below $32^{\circ} \mathrm{C}$. Although one of the promotional elements of ceramic drills is less wear and therefore less heat production, this was not verified by our study. There was no statistical difference in heat production between these 2 systems. These results indicate that these 2 systems can be sterilized and re-used at least 25 times, without the danger of thermonecrosis, in bone. System B has the smallest edge angle, possibly indicating a higher potential for wear, which would translate into increased heat production after multiple uses. Also system B has demonstrated more chipping comparing to system A. However, in this study no difference was found in heat generation between both systems. System A and B generated more heat as sterilized and used. Base bone temperature was $24^{\circ} \mathrm{C}$. The maximum temperature recorded for system A was $31.3^{\circ} \mathrm{C}$ and for system B was $31.2^{\circ} \mathrm{C}$. The difference in temperature between base bone and the last maximum recorded temperature after 25 times were calculated. Difference in Temperature was $6.1^{\circ} \mathrm{C}$ for system $\mathrm{A}$ and $6.2^{\circ} \mathrm{C}$ for system $\mathrm{B}$. The normal human temperature is $37^{\circ} \mathrm{C}$. Having this in mind a $6^{\circ} \mathrm{C}$ change of temperature in this study suggest the safe use of both system A and B without generation of heat exceeding $47^{\circ} \mathrm{C}$. It's difficult to measure the exact heat produce at the osteotomy wall of the preparation. The temperatures were measured 0.5 
mm away from the osteotomy site. All temperatures recorded are close proximate to the heat generated at the osteotomy walls. Sequential drilling removes different amounts of bone depending on the various drill sizes and number of drills in the implant drill system. Figure 9 and 10 shows the effect of wear on the 2 implant drill systems were used. The ceramic drills demonstrated chipping of the cutting edge while stainless steel showed roughened edges. System A and B have 3 cutting drills in its sequence; system A is a stainless steel drills. System B is ceramic drills. Comparing SEM for both systems in this study explained the increase in temperature with increase of number of uses. The findings in this study support the finding By Albertson (1984) that as the number of uses increase the temperature increase too. There is a very strong suggestion that drill sharpness affects heat generation. This study demonstrated that with increased use, implant drills tend to generate more heat. Systems A and System B appear to stay within the accepted temperature parameters, at least up to 25 uses. System B showed slightly more wear than system A. However, both systems are safe to be used up to 25 times. More research is needed to firmly establish a link between drill design and increased temperatures 
Figure 9. Before and after scans for ceramic drills

Before (Ceramic)

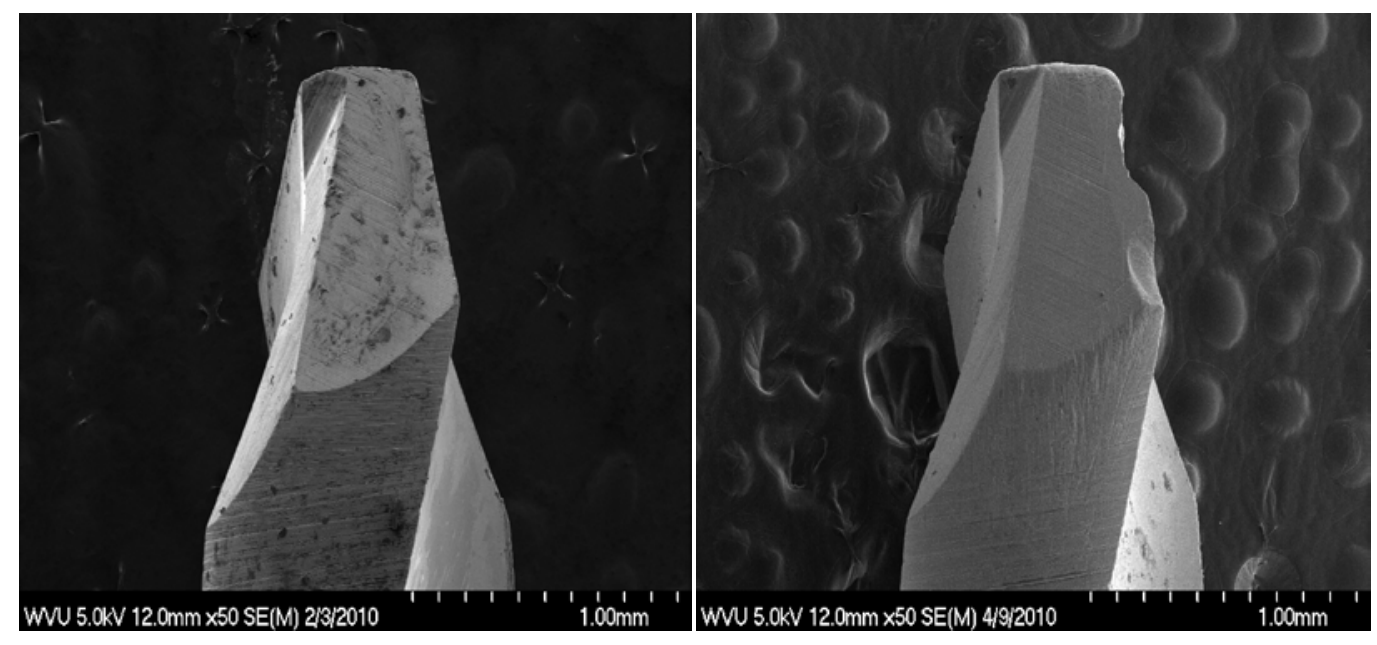

After (Ceramic)

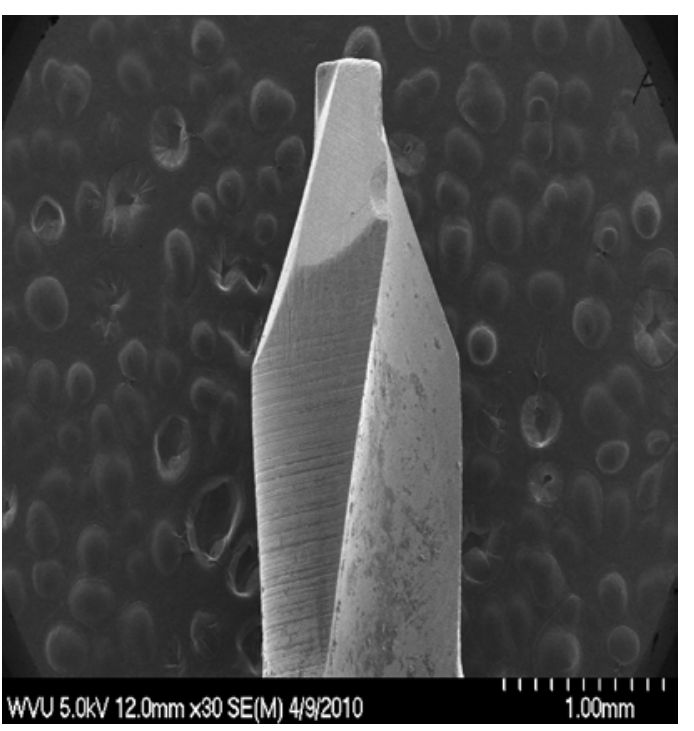




\section{Figure 10. Before and after scans for stainless steel drills}

Before Steel
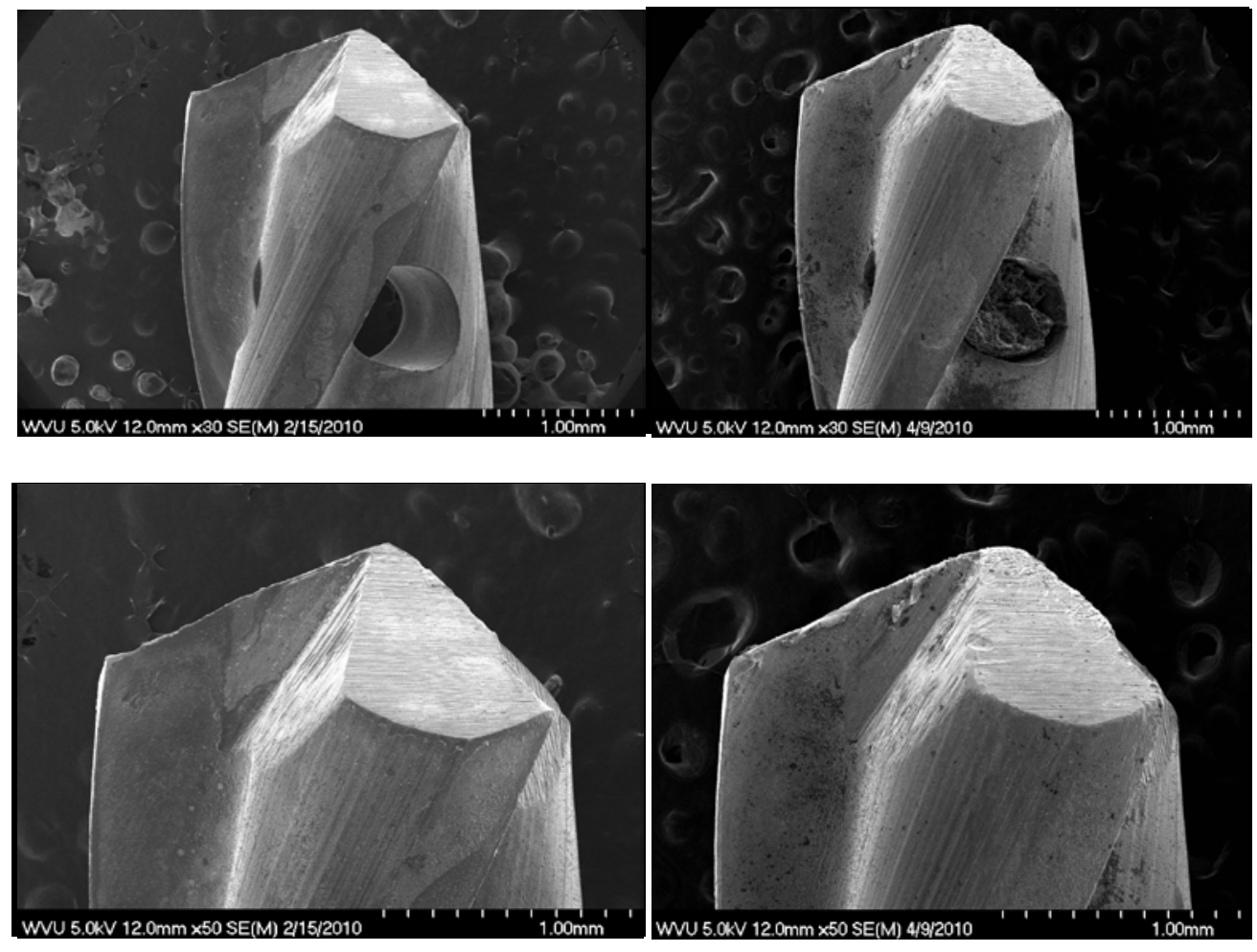

\section{Chapter V: Summary and Conclusion}

\section{Summary:}

Excessive trauma during dental implant surgery is considered an important factor of implant failure. Thermonecrosis can result from an increase bone temperature. Repeated use of implant drills progressively increases their wear and decreases their efficiency, thus producing more frictional heat. Multiple factors have been linked to heat production during surgery including drill sharpness. The goal of this research was to focus on the heat generated by an implant drill and how the factor of wear effects the heat generated when drilling through bone.

Two implant drill systems were evaluated in vitro using bovine back rib bone. System A consisted of stainless steel surgical drills sizes 2.3, 2.8 and 3.4 mmD (Tapered Screw- Vent surgical 
drills by Zimmer Dental). System B was alumina-toughened zirconia ceramic surgical drills sizes 2.0, 2.8 and 3.5mmD ( Thommen Medical). Transverse bovine rib sections were obtained and stored at -20 C. The bovine bone was defrosted to room temperature before use. Using a template, one canal 10mm long was drilled for the thermocouple. Two marks using a sharp pencil were made next to the thermocouple canal and $0.5 \mathrm{~mm}$ away from the largest final size drill at each side. The thermocouple was connected to the personal dag/3000 series model 1136-0901 IQtech for data collection and temperature recording. Sterilization of the drills before the first use and after each osteotomy was preformed. Sequential drilling (by size) was preformed and the maximum temperatures were recorded for all six drills used for both systems A and B. Speed of 1500 Rpm and external irrigation $40 \mathrm{ml} / \mathrm{sec}$ were used. Maintaining a constant weight of $2.4 \mathrm{~kg}$ applied to the hand peace while drilling. After each trial the drills were sterilized and the preparation repeated twenty five times for each system. All the ostetomies were performed by the same clinician to simulate a real clinical setting situation. After twenty five times of usage. Total of fifty osteotomies. Both implant drills system were scanned using Scanning Electron Microscope before the first use and after the last use.

The study showed no significant differences between the two systems in wear and heat generated. Both systems A and B showed an increase in temperature as the drills were used. It was also found that significant wear occurred to both systems after twenty five usages. The maximum temperature for system A was $31.3^{\circ} \mathrm{C}$ and for system B was $31.2^{\circ} \mathrm{C}$. SEMs taking before and after the trials showed significant wear to both systems. Chips and cracking at the drill edges were observed. The implant multiuse drills used in this study appear to be safe for use up to 25 times without resulting in bone temperatures that are harmful. 


\section{Conclusion:}

Wear and decrease in drill sharpness plays a major role in heat production and result in the increase of temperature readings seen in both systems. Drill sharpness and mechanical property significantly affect cutting efficiency and durability. After multiple uses and sterilization of each drilling system, the temperature within the bone increased with each trial. Both drilling systems generated more heat as a result of friction between the drilling systems and the bone due to the dulling of the drills. From a heat generation stand point, no different between stainless steel and ceramic drills were found. The SEM photographs taken before and after the experiment show significant wear to the drilling systems as a result of repeated osteotomies. It can be suggested that failure to follow the manufacturer's limits on usage of each drilling system will result in an increase in temperature of the bone as the drills wear with an increased the risk of osteonecrosis. 


\section{REFERENCES:}

1. Abouzgia MB, James DF. Measurements of shaft speed while drilling through bone. J Oral Maxillofac Surg 1995;53: 1308-1315.

2. Adell R, Eriksson B, Lekholm U, Brånemark P-I, Jemt T. A long-term follow-up study of osseointegrated implants in the treatment of totally edentulous jaws. Int J Oral Maxillo-facial Implants 1990;5:347-359.

3. Adell R, Lekholm U, Brånemark P-I. Surgical procedures. In: Branemark P-I, Zarb GA, AlbrektssonT. Tissue-Integrated Prostheses: Osseointegration in Clinical Dentistry. Chicago: Quintessence, 1985:211-232.

4. Adell R, Lekholm U, Brånemark P-I. Surgical procedures. In: Branemark P-I, Zarb GA, AlbrektssonT. Tissue-Integrated Prostheses: Osseointegration in Clinical Dentistry. Chicago: Quintessence, 1985:211-232.

5. Agren E, Arwill T. High speed or conventional dental equipment for the removal of bone in oral surgery. III. A histologic and microradiographic study on bone repair in the rabbit. Acta Odontol Scand 1968;26:223-246.

6. Albrektsson T, Linder L. Intravital, long-term follow-up of autologous, experimental bone grafts. Arch Orthop Trauma Surg 1981;98:189-195.

7. Albrektsson T. Direct bone anchorage of dental implants. J Prosthet Dent 1983;50:255-261.

8. Albrektsson T: Bone tissue response, in Brånemark P-I, Zarb GA, Albrektsson T: TissueIntegrated Prostheses: Osseointegration in Clinical Dentistry. Chicago, IL, Quintessence, 1985, pp129-143.

9. Andrianne Y, Wagenknecht M, Donkerwolcke M, Zur-buchen C, Burny F. External fixation pin: An in vitro general investigation. Orthopedics 1987;10:1507-1516. 
10. Branemark PI, Chien S Li S. Heat shock-induced necrosis and apoptosis in osteoblast. J orthop res.1999 Nov, 17(6):891-9.

11. Brånemark P-I. Osseointegration and its experimental back-ground. J Prosthet Dent 1983;50:399-410.

12. Chacon Ge, Bower DL, Larsen PE, McGlumphy EA, Beck FM. Heat produced by 3 implants drill systems after repeated drilling and sterilization. J Oral Maxillofacial Surg.2006 Feb; 64(2):265-29.

13. Chhabra A, Westerlund LE. Managements of proximal femoral shaft fracture in osteopetrosis. Orthopedics.2005,28(6):587-592

14. Cordioil G, Majzoub Z. Heat generated during implant site preparation. Int J Oral maxillofacial Implants.1997Mar-Apr;12(2):186-193.

15. Davidson SR, James DF. Drilling in bone: modeling heat generation and temperature distribution. J Biomech Eng 2003;125(3):305-314.

16. Ercoli C, Funkenbush P, Lee H, Moss M, Graser. The influence of drill on cutting efficiency and heat production during osteotomy preparation for dental implants: A study of drill durability. Int J Oral Maxillofac Implants 2004;19:335-349.

17. Eriksson RA. Heat Induced Bone Tissue Injury. An In vivo Investigation of Heat Tolerance of Bone Tissue and Temperature Rise In the Drilling of Cortical Bone. Goteborge , University of Goteborge, Sweden,1984.

18. Eriksson RA, Adell R. Temperatures during drilling for the placement of implants using the osseointegration technique. J Oral Maxillofacial Surg 1986;44:4-7.

19. Eriksson AR, Albrektsson T, Albrektsson B. Heat caused by drilling cortical. Temperature measured in vivo in patient and animals. Acta Orthp Scand 1984;55:629-631. 
20. Eriksson RA, Albrektsson T. The effect of heat on bone regeneration: An experimental study in the rabbit using the bone growth chamber. J Oral Maxillofac Surg 1984;42: 705-711.

21. Eriksson RA, Albrektsson T, Magnusson B. Assessment of bone viability after heat trauma. A histological, histochemical and vital microscopic study in the rabbit. Scand J Plast Reconstr Surg 1984;18:261-268.

22. Eriksson RA, Albrektsson T. Heat caused by drilling cortical bone. Temperature measured in vivo in patients and animals. Acta Orthop Scand 1984;55:629-631.

23. Eriksson A, Albrektsson T, Grane B, McQueen D. Thermal injury to bone: A vital-microscopic description of heat effects. Int J Oral Surg 1982;11:115-121.

24. Eriksson RA. Alberktsson T. Temperature threshold level for heat-Induced bone tissue injury: A Vital-microscopic study in the rabbit .J Prosthet dent 1983,50:101-107.

25. Friberg B, Jemt T, Lekholm U. Early failures in 4,641 consecutively placed Branemark dental implants: A study from stage 1 surgery to the connection of completed prostheses. Int J Oral Maxillofac Implants 1991;6:142-146.

26. Harris BH, Kohles SS. Effects of mechanical and thermal fatigue on dental drill performance. Int J Oral Maxillofac Implants 2001;16:819-826.

27. Hanson HA, Albrektsson T, Brånemark P-I. Structural aspects of the interface between tissue and titanium implants. J Prosthet Dent 1983;50:108-113.

28. Hobkirk JA, Rusiniak K. Investigation of variable factors in drilling bone. J Oral Surg 1977;35:968-973.

29. Iyer S, Weiss C, Mehta A. Effects of drill speed on heat production and the rate and quality of bone formation in dental implant osteotomies. PartII:Relationship between drill speed and healing. Int J Prosthodont 1997;10:411-414. 
30. Jacobs CH, Pope MH, Berry JT, Hoagland F. A study of the bone machining process orthogonal cutting. J Biomech 1974;7:131-136.

31. Jaffin RA, Berman C. The excessive loss of Branemark fix-tures in type IV bone: A 5-year analysis. J Periodontol 1991;62:2-4.

32. Jemt T. Implant treatment in resorbed edentulous upper jaws: A three-year follow-up study on 70 patients. Clin Oral Implants Res 1993;4:187-194.

33. Jochum RM, Reichart PA. Influence of multiple use of Timedur-titanium cannon drills: Thermal response and scanning electron microscopic findings. Clin Oral Implants Res 2000;11:139-143.

34. Johnson AT. Biological Process Engineering: An Analogical Approach to Fluid Flow, Heat Transfer, and Mass Transfer Applied to Biological Systems. New York: John Wiley \& Sons, 1998:262-493.

35. Kohles SS, Bowers JR, Vailas AC, Vanderby R Jr. Ultrasonic wave velocity measurement in small polymeric and cortical bone specimens. J Biomech Eng 1997;119:232-236.

36. Komatsu, Yosshiaki Hata. Heat in bone preparation of implant sites: Heat analysis by real time thermography. Oral \& maxillofacial implant1992:7:212-219.

37. Lavelle C, Wedgwood D. Effect of internal irrigation on frictional heat generated from bone drilling. J Oral Surg 1980;38:499-503.

38. Matthews LS, Hirsch C. Temperatures measured in human cortical bone when drilling. Am J Bone Joint Surg 1972;54: 297-308.

39. Mazorow HB. Bone repair after experimentally produced defects. J Oral Surg 1960;18:107-115.

40. Okada K, Watanabe F, Watanabe Y, Takamura M, Hata Y. Drill efficiency at repeated use. IMZ implant drill system. Nippon Koku Inpuranto Gakkaishi 2000;13:47-51. 
41. Scarno A, Carinici F, Quaranta A, Di Iorio D, Assenza B, Piattelli A. Effect of bur wear during implants site preparation: an in vitro study. Int J Immunopathol Pharmacol 2007;20:23-26.

42. Seddlin ED, Hirsch C. Factors affecting the determination of the physical properties of femoral cortical bone. Acta orthop Scand 1966;37:29-48.

43. Thompson HC. Effect of drilling into bone. J oral surgery 1985.

44. Vanderby R Jr, Kohles SS. Thermographic stress analysis in cortical bone. J Biomech Eng 1991;113:418-422. 23. Dick.

45. Watanabe F, Tawada Y, Komatsu S, Hata Y. Heat distribution in bone during preparation of implants site: heat analysis by real-time thermography Int J Maxillofac Implants1992;7:212219.

46. Wiggins KL, Malkin S. Drilling of bone. J Biomech 1976;9:553-559.

47. Yacker Mj, Klein M. The effect of irrigation on osteotomy depth and bur diameter. Int J oral Maxillofacial Implants; 1996 Sep-Oct;11(5):634-8. 